\title{
Exogenous Proline and Glycine Betaine Mediated Upregulation of Antioxidant Defense and Glyoxalase Systems Provides Better Protection against Salt-Induced Oxidative Stress in Two Rice (Oryza sativa L.) Varieties
}

\author{
Mirza Hasanuzzaman, ${ }^{1}$ Md. Mahabub Alam, ${ }^{2}$ Anisur Rahman, ${ }^{1,2}$ Md. Hasanuzzaman, \\ Kamrun Nahar, ${ }^{2,3}$ and Masayuki Fujita ${ }^{2}$ \\ ${ }^{1}$ Department of Agronomy, Faculty of Agriculture, Sher-e-Bangla Agricultural University, Sher-e-Bangla Nagar, \\ Dhaka 1207, Bangladesh \\ ${ }^{2}$ Laboratory of Plant Stress Responses, Department of Applied Biological Science, Faculty of Agriculture, Kagawa University, \\ 2393 Ikenobe, Miki-cho, Kita-gun, Kagawa 761-0795, Japan \\ ${ }^{3}$ Department of Agricultural Botany, Faculty of Agriculture, Sher-e-Bangla Agricultural University, Sher-e-Bangla Nagar, \\ Dhaka 1207, Bangladesh
}

Correspondence should be addressed to Mirza Hasanuzzaman; mhzsauag@yahoo.com

Received 25 February 2014; Revised 9 May 2014; Accepted 9 May 2014; Published 3 June 2014

Academic Editor: Qaisar Mahmood

Copyright (C) 2014 Mirza Hasanuzzaman et al. This is an open access article distributed under the Creative Commons Attribution License, which permits unrestricted use, distribution, and reproduction in any medium, provided the original work is properly cited.

\begin{abstract}
The present study investigates the roles of exogenous proline (Pro, $5 \mathrm{mM}$ ) and glycine betaine (GB, $5 \mathrm{mM}$ ) in improving salt stress tolerance in salt sensitive (BRRI dhan49) and salt tolerant (BRRI dhan54) rice (Oryza sativa L.) varieties. Salt stresses (150 and $300 \mathrm{mM} \mathrm{NaCl}$ for $48 \mathrm{~h}$ ) significantly reduced leaf relative water (RWC) and chlorophyll (chl) content and increased endogenous Pro and increased lipid peroxidation and $\mathrm{H}_{2} \mathrm{O}_{2}$ levels. Ascorbate (AsA), glutathione (GSH) and GSH/GSSG, ascorbate peroxidae (APX), monodehydroascorbate reductase (MDHAR), dehydroascorbate reductase (DHAR), glutathione reductase (GR), glutathione peroxidase (GPX), catalase (CAT), and glyoxalase I (Gly I) activities were reduced in sensitive variety and these were increased in tolerant variety due to salt stress. The glyoxalase II (Gly II), glutathione S-transferase (GST), and superoxide dismutase (SOD) activities were increased in both cultivars by salt stress. Exogenous Pro and GB application with salt stress improved physiological parameters and reduced oxidative damage in both cultivars where BRRI dhan54 showed better tolerance. The result suggests that exogenous application of Pro and GB increased rice seedlings' tolerance to salt-induced oxidative damage by upregulating their antioxidant defense system where these protectants rendered better performance to BRRI dhan54 and Pro can be considered as better protectant than GB.
\end{abstract}

\section{Introduction}

Crop plants, as sessile organisms, face a number of environmental adversities termed as abiotic stress which includes soil salinity, water deficit, extremely high or low temperatures, toxic metals, waterlogging, elevated ozone, and ultraviolet radiation, which all create a barrier for proper growth, metabolism, and productivity of crop plants [1-10]. Among the environmental stresses soil salinity is a widespread environmental problem that has been found to affect more than 77 million hectares or $5 \%$ of the cultivable land of the universe $[11,12]$. Salinity adversely affects the plant growth and productivity. The yield reduction due to salt stress may account for substantial reduction of the average yield of major crops by more than $50 \%$ [13]. The nature of damages due to salt stress is very complex because it causes both osmotic stress and ionic 
toxicity [7]. At molecular level, one of the common events in plants grown under salt stress is the considerable increases in reactive oxygen species (ROS) such as singlet oxygen $\left({ }^{1} \mathrm{O}_{2}\right)$, superoxide radical $\left(\mathrm{O}_{2}{ }^{--}\right)$, hydrogen peroxide $\left(\mathrm{H}_{2} \mathrm{O}_{2}\right)$, and hydroxyl radical $\left({ }^{\circ} \mathrm{OH}\right)$ [2]. However, the production of ROS greatly depends on the degree and duration of the imposition of stress and types of crop as well [2]. Considering the destructive effects of salt-induced oxidative stress in plants it is crucial to keep the ROS level below the toxic limit. Plants always try to keep well-developed enzymatic and nonenzymatic antioxidant defense system ready to encounter the deleterious effects of ROS [2]. The enzymatic system includes the four enzymes of the ascorbate-glutathione (AsA-GSH) cycle: ascorbate peroxidase (APX), monodehydroascorbate reductase (MDHAR), dehydroascorbate reductase (DHAR), and glutathione reductase (GR) as well as other enzymes like superoxide dismutase (SOD), catalase (CAT), glutathione peroxidase (GPX), and glutathione $S$-transferase (GST). The nonenzymatic antioxidants include ascorbic acid (AsA), glutathione (GSH), phenolic compounds, alkaloids, nonprotein amino acids, and $\alpha$-tocopherols. They act together in scavenging or detoxifying ROS and subsequent protection of plant cells from oxidative damage $[2,4]$. However, this system acts differently in different plant species and cultivars and it was observed that the enhancement of the antioxidant defense system is often correlated with salt stress tolerance [4, 7]. Methylglyoxal (MG) is another highly reactive cytotoxic which is produced largely under abiotic stress including salinity $[14,15]$ and leads to damages to proteins, lipids, and DNA $[16,17]$. In line with antioxidant defense system plants also possess glyoxalase system consisting of two enzymes: glyoxalase I (Gly I) and glyoxalase II (Gly II); those can detoxify MG. Enzymes of the glyoxalase system are found to regulate environmental stresses including salinity as reported in many plant studies $[2,3,10,18]$. It was reported that the coordinated upregulation of both the antioxidant defense and glyoxalase systems is necessary to attain significant tolerance to oxidative stress $[2,6]$.

It is an urgent task of plant biologists to explore suitable mechanisms of developing salt tolerant crop plants that can produce sufficient yield under adverse condition. In recent decades, many researchers have been trying to find the ways to alleviate salt stress or to overcome salt injury in plants. Among them exogenous application of substances such as osmoprotectants, phytohormones, antioxidants, and trace elements came to attention in recent times $[4,19,20]$.

In response to various environmental stresses, plants demonstrate a variety of adaptive mechanisms to counteract them. Since one of the primary responses under salt stress is osmotic adjustment, compatible solutes such as proline (Pro) and glycine betaine (GB) are very common to be accumulated during salt stress and play a fundamental role in osmotic adjustment in plants [21]. These compatible solutes are accumulated in the cytosol without disturbing intracellular biochemistry, which ameliorate the detrimental effects of salinity [22-25].

In many plant species increased accumulation of Pro and GB were observed as an indicator of salt stress tolerance
$[22,26]$. However, most of the plants, especially under elevated levels of salt, cannot synthesize sufficient amount of these osmoregulators. In many recent reports exogenous applications of Pro and GB were found to act as protectants under salt stress $[12,25,27]$. Besides osmoprotection, Pro and GB also showed their roles in elimination of oxidative stress by triggering the antioxidant defense and also glyoxalase system $[25,28-32]$.

Although there are several reports on the role of Pro and GB in salt stress tolerance in terms of growth and physiology, few investigations have been done on the effects of exogenous Pro and GB on both antioxidant defense and the glyoxalase system in rice. Therefore, we investigated the protective effects of these osmoprotectants on the antioxidant defense and glyoxalase systems in rice seedlings grown under saline media. We also investigated the comparative performance of two modern rice varieties differing in their salt tolerance to know their actual adaptive mechanisms under salt stress with or without osmoprotectants.

\section{Materials and Methods}

2.1. Plant Materials and Stress Treatments. Seeds of two rice (Oryza sativa L.) cultivars, cv. BRRI dhan 49 (salt sensitive) and cv. BRRI dhan54 (salt tolerant) were collected from Bangladesh Rice Research Institute (BRRI) and surfacesterilized with $70 \%$ ethanol for $10 \mathrm{~min}$ followed by washing several times with sterilized distilled water. Seeds were then soaked for $24 \mathrm{~h}$ in the dark. Seeds were sown on plastic nets upon plastic beakers containing distilled water and kept in the dark at $28 \pm 2^{\circ} \mathrm{C}$ for germination. After $48 \mathrm{~h}$, uniformly germinated seeds were transferred to growth chamber with controlled conditions (light intensity, $100 \mu \mathrm{mol} \mathrm{m}{ }^{-2} \mathrm{~s}^{-1}$; temperature, $25 \pm 2^{\circ} \mathrm{C}$; relative humidity, 65-70\%) and during the growing period hyponex solution (Hyponex, Japan) was used as nutrient. Two levels of salt stresses $(150$ and $300 \mathrm{mM}$ $\mathrm{NaCl}$ ) were imposed on fourteen-day-old rice seedlings with, without $5 \mathrm{mM}$ proline [L (-) Proline, Wako, Japan] and betaine (Betaine, Wako, Japan), and where these protectants were sprayed twice a day mixing with the wetting agent $0.02 \%$ Tween 20 (Tween 20, Wako, Japan). Control plants were grown with Hyponex solution only. Data were taken after $48 \mathrm{~h}$ of $\mathrm{NaCl}$ treatment. The experiment was repeated three times $(n=3)$ under the same conditions.

2.2. Measurement of Relative Water Content. Relative water content (RWC) was measured according to Barrs and Weatherley [33]. Leaf laminas were weighed (fresh wt, FW) and then immediately floated on distilled water in a petri dish for $8 \mathrm{~h}$ in the dark. Turgid weights (TW) were obtained after drying excess surface water with paper towels. Dry weights (DW) were measured after drying at $80^{\circ} \mathrm{C}$ for $48 \mathrm{~h}$. The calculation was done using the following formula:

$$
\mathrm{RWC}(\%)=\frac{\mathrm{FW}-\mathrm{DW}}{\mathrm{TW}-\mathrm{DW}} \times 100 \text {. }
$$

2.3. Determination of Chlorophyll Content. Chlorophyll content was determined by homogenizing leaf samples $(0.5 \mathrm{~g})$ 
with $10 \mathrm{~mL}$ of acetone $(80 \% \mathrm{v} / \mathrm{v})$ followed by centrifuging at $5,000 \times \mathrm{g}$ for $10 \mathrm{~min}$. The absorbance was measured with a $\mathrm{UV}$-visible spectrophotometer at specified wave length and chl contents were calculated using the equations proposed by Arnon [34].

2.4. Determination of Proline Content. Free proline in leaf tissues was appraised following the protocol of Bates et al. [35]. Fresh leaf tissue ( $0.5 \mathrm{~g}$ ) was homogenized in $10 \mathrm{~mL}$ of $3 \%$ sulfosalicylic acid in ice. The homogenate was centrifuged at $11,500 \times \mathrm{g}$ for $15 \mathrm{~min}$. Two $\mathrm{mL}$ of the filtrate was mixed with $2 \mathrm{~mL}$ of acid ninhydrin and $2 \mathrm{~mL}$ of glacial acetic acid. After incubation at $100^{\circ} \mathrm{C}$ for $1 \mathrm{~h}$ it was cooled and $4 \mathrm{~mL}$ of toluene was added. The optical density of the chromophore containing toluene was read spectrophotometrically at $520 \mathrm{~nm}$ using toluene as a blank. The amount of Pro was determined by comparison with a standard curve.

2.5. Measurement of Lipid Peroxidation. The level of lipid peroxidation was measured by estimating MDA, using thiobarbituric acid (TBA) as the reactive material following the method of Heath and Packer [36] with slight modifications. The leaf samples $(0.5 \mathrm{~g})$ were homogenized in $3 \mathrm{~mL}$ $5 \%(\mathrm{w} / \mathrm{v})$ trichloroacetic acid (TCA) and the homogenate was centrifuged at $11,500 \times \mathrm{g}$ for $10 \mathrm{~min}$. One $\mathrm{mL}$ supernatant was mixed with $4 \mathrm{~mL}$ of TBA reagent $(0.5 \%$ of TBA in $20 \%$ TCA). The reaction mixture was heated at $95^{\circ} \mathrm{C}$ for $30 \mathrm{~min}$ in a water bath and then quickly cooled in an ice bath and centrifuged at $11,500 \times \mathrm{g}$ for $15 \mathrm{~min}$. The absorbance of the colored supernatant was measured at $532 \mathrm{~nm}$ and was corrected for nonspecific absorbance at $600 \mathrm{~nm}$. The concentration of MDA was calculated by using the extinction coefficient of $155 \mathrm{mM}^{-1} \mathrm{~cm}^{-1}$ and expressed as nmol of MDA $\mathrm{g}^{-1}$ fresh weight.

2.6. Measurement of $\mathrm{H}_{2} \mathrm{O}_{2} \cdot \mathrm{H}_{2} \mathrm{O}_{2}$ was assayed according to the method described by $\mathrm{Yu}$ et al. [37]. $\mathrm{H}_{2} \mathrm{O}_{2}$ was extracted by homogenizing $0.5 \mathrm{~g}$ of leaf samples with $3 \mathrm{~mL}$ of $50 \mathrm{mM}$ potassium-phosphate (K-P) buffer $(\mathrm{pH} 6.5)$ at $4^{\circ} \mathrm{C}$. The homogenate was centrifuged at $11,500 \times \mathrm{g}$ for $15 \mathrm{~min}$. Three milliliter of supernatant was mixed with $1 \mathrm{~mL}$ of $0.1 \% \mathrm{TiCl}_{4}$ in $20 \% \mathrm{H}_{2} \mathrm{SO}_{4}(\mathrm{v} / \mathrm{v})$ and kept in room temperature for $10 \mathrm{~min}$. After that the mixture was again centrifuged at $11,500 \times \mathrm{g}$ for $15 \mathrm{~min}$. The optical absorption of the supernatant was measured spectrophotometrically at $410 \mathrm{~nm}$ to determine the $\mathrm{H}_{2} \mathrm{O}_{2}$ content $\left(\epsilon=0.28 \mu \mathrm{M}^{-1} \mathrm{~cm}^{-1}\right)$ and expressed as nmol g ${ }^{-1}$ fresh weight.

2.7. Extraction and Measurement of Ascorbate and Glutathione. Rice leaves ( $0.5 \mathrm{~g}$ fresh weight) were homogenized in $3 \mathrm{~mL}$ ice-cold acidic extraction buffer (5\% metaphosphoric acid containing $1 \mathrm{mM}$ EDTA) using a mortar and pestle. Homogenates were centrifuged at $11,500 \times \mathrm{g}$ for $15 \mathrm{~min}$ at $4^{\circ} \mathrm{C}$ and the supernatant was collected for analysis of ascorbate and glutathione.

Ascorbate content was determined following the method of Huang et al. [38] with some modifications. The supernatant was neutralized with $0.5 \mathrm{M}$ K-P buffer ( $\mathrm{pH}$ 7.0). The AsA was assayed spectrophotometrically at $265 \mathrm{~nm}$ in $100 \mathrm{mM} \mathrm{K}$ $\mathrm{P}$ buffer ( $\mathrm{pH} 7.0$ ) with 0.5 unit of ascorbate oxidase (AO). A specific standard curve with AsA was used for quantification.

The glutathione pool was assayed according to previously described methods [37] with modifications [39] utilizing $200 \mu \mathrm{L}$ of aliquots of supernatant neutralized with $300 \mu \mathrm{L}$ of $0.5 \mathrm{M} \mathrm{K}-\mathrm{P}$ buffer ( $\mathrm{pH} 7.0$ ). Based on enzymatic recycling, GSH is oxidized by $5,5^{\prime}$-dithio-bis (2-nitrobenzoic acid) (DTNB) and reduced by NADPH in the presence of GR, and glutathione content is evaluated by the rate of absorption changes at $412 \mathrm{~nm}$ of 2-nitro-5-thiobenzoic acid (NTB) generated from the reduction of DTNB. GSSG was determined after removal of GSH by 2-vinylpyridine derivatization. Standard curves with known concentrations of GSH and GSSG were used. The content of GSH was calculated by subtracting GSSG from total GSH.

2.8. Determination of Protein. The protein concentration of each sample was determined following the method of Bradford [40] using BSA as a protein standard.

2.9. Enzyme Extraction and Assays. Using a pre-cooled mortar and pestle, $0.5 \mathrm{~g}$ of leaf tissue was homogenized in $1 \mathrm{~mL}$ of $50 \mathrm{mM}$ ice-cold K-P buffer ( $\mathrm{pH} 7.0$ ) containing $100 \mathrm{mM} \mathrm{KCl}$, $1 \mathrm{mM}$ ascorbate, $5 \mathrm{mM} \beta$-mercaptoethanol and $10 \%(\mathrm{w} / \mathrm{v})$ glycerol. The homogenates were centrifuged at $11,500 \times \mathrm{g}$ for $10 \mathrm{~min}$ and the supernatants were used for determination of enzyme activity. All procedures were performed at $0-4^{\circ} \mathrm{C}$.

LOX (EC 1.13.11.12) activity was estimated according to the method of Doderer et al. [41] by monitoring the increase in absorbance at $234 \mathrm{~nm}$ using linoleic acid as a substrate. The activity was calculated using the extinction coefficient $\left(25 \mathrm{mM}^{-1} \mathrm{~cm}^{-1}\right)$ and expressed as units ( $1 \mathrm{nmol}$ of substrate oxidized per minute) per mg protein.

SOD (EC 1.15.1.1) activity was estimated according to Beyer and Fridovich [42] which was based on xanthinexanthine oxidase system. The reaction mixture contained KP buffer (50 mM), NBT (2.24 mM), catalase (0.1 units), xanthine oxidase $(0.1$ units), xanthine $(2.36 \mathrm{mM})$, and enzyme extract. Catalase was added to avoid the $\mathrm{H}_{2} \mathrm{O}_{2}$-mediated possible inactivation of CuZn-SOD. SOD activity was expressed as units (amount of enzyme required to inhibit NBT reduction by $50 \%$ ) $\mathrm{min}^{-1} \mathrm{mg}^{-1}$ protein.

CAT (EC: 1.11.1.6) activity was measured according to the method of Hasanuzzaman et al. [2] by monitoring the decrease of absorbance at $240 \mathrm{~nm}$ for 1 min caused by the decomposition of $\mathrm{H}_{2} \mathrm{O}_{2}$. The reaction mixture contained $50 \mathrm{mM}$ K-P buffer ( $\mathrm{pH}$ 7.0), $15 \mathrm{mM} \mathrm{H}_{2} \mathrm{O}_{2}$ and enzyme solution in a final volume of $700 \mu \mathrm{L}$. The activity was calculated using the extinction coefficient of $39.4 \mathrm{M}^{-1} \mathrm{~cm}^{-1}$.

APX (EC: 1.11.1.11) activity was assayed following the method of Nakano and Asada [43]. The reaction buffer solution contained $50 \mathrm{mM} \mathrm{K}-\mathrm{P}$ buffer ( $\mathrm{pH}$ 7.0), 0.5 mM AsA, $0.1 \mathrm{mM} \mathrm{H}_{2} \mathrm{O}_{2}, 0.1 \mathrm{mM}$ EDTA, and enzyme extract in a final volume of $700 \mu \mathrm{L}$. The activity was measured by observing the decrease in absorbance at $290 \mathrm{~nm}$ for 1 min using an extinction coefficient of $2.8 \mathrm{mM}^{-1} \mathrm{~cm}^{-1}$. 
MDHAR (EC: 1.6.5.4) activity was determined by the method of Hossain et al. [44]. The reaction mixture contained $50 \mathrm{mM}$ Tris- $\mathrm{HCl}$ buffer ( $\mathrm{pH}$ 7.5), $0.2 \mathrm{mM}$ NADPH, $2.5 \mathrm{mM}$ AsA, 0.5 unit of $\mathrm{AO}$ and enzyme solution in a final volume of $700 \mu \mathrm{L}$. The activity was calculated from the change in ascorbate at $340 \mathrm{~nm}$ for $1 \mathrm{~min}$ using an extinction coefficient of $6.2 \mathrm{mM}^{-1} \mathrm{~cm}^{-1}$.

DHAR (EC: 1.8.5.1) activity was determined by the procedure of Nakano and Asada [43]. The reaction buffer contained $50 \mathrm{mM}$ K-P buffer ( $\mathrm{pH} 7.0), 2.5 \mathrm{mM}$ GSH, and $0.1 \mathrm{mM}$ DHA. The activity was calculated from the change in absorbance at $265 \mathrm{~nm}$ for $1 \mathrm{~min}$ using extinction coefficient of $14 \mathrm{mM}^{-1} \mathrm{~cm}^{-1}$.

GR (EC: 1.6.4.2) activity was measured by the method of Hasanuzzaman et al. [3]. The reaction mixture contained 0.1 M K-P buffer (pH 7.0), 1 mM EDTA, 1 mM GSSG, 0.2 mM $\mathrm{NADPH}$, and enzyme solution in a final volume of $1 \mathrm{~mL}$. The decrease in absorbance at $340 \mathrm{~nm}$ was recorded for $1 \mathrm{~min}$. The activity was calculated using an extinction coefficient of $6.2 \mathrm{mM}^{-1} \mathrm{~cm}^{-1}$.

GST (EC: 2.5.1.18) activity was determined spectrophotometrically by the method of Hossain et al. [45] with some modifications. The reaction mixture contained $100 \mathrm{mM}$ Tris-HCl buffer (pH 6.5), 1.5 mM GSH, 1 mM 1-chloro-2,4dinitrobenzene (CDNB), and enzyme solution in a final volume of $700 \mu \mathrm{L}$. The increase in absorbance was measured at $340 \mathrm{~nm}$ for $1 \mathrm{~min}$. The activity was calculated using the extinction coefficient of $9.6 \mathrm{mM}^{-1} \mathrm{~cm}^{-1}$.

GPX (EC: 1.11.1.9) activity was measured as described by Elia et al. [46] with slight modification using $\mathrm{H}_{2} \mathrm{O}_{2}$ as a substrate. The reaction mixture consisted of $100 \mathrm{mM} \mathrm{K}-\mathrm{P}$ buffer ( $\mathrm{pH}$ 7.0), $1 \mathrm{mM}$ EDTA, $1 \mathrm{mM} \mathrm{NaN}_{3}, 0.12 \mathrm{mM}$ NADPH, $2 \mathrm{mM}$ GSH, 1 unit GR, $0.6 \mathrm{mM} \mathrm{H}_{2} \mathrm{O}_{2}$, and $20 \mu \mathrm{L}$ of sample solution. The oxidation of NADPH was recorded at $340 \mathrm{~nm}$ for $1 \mathrm{~min}$ and the activity was calculated using the extinction coefficient of $6.62 \mathrm{mM}^{-1} \mathrm{~cm}^{-1}$.

Glyoxalase I (EC: 4.4.1.5) assay was carried out according to Hasanuzzaman et al. [2]. Briefly, the assay mixture contained $100 \mathrm{mM}$ K-P buffer ( $\mathrm{pH}$ 7.0), $15 \mathrm{mM}$ magnesium sulfate, $1.7 \mathrm{mM} \mathrm{GSH}$ and $3.5 \mathrm{mM}$ MG in a final volume of $700 \mu \mathrm{L}$. The increase in absorbance was recorded at $240 \mathrm{~nm}$ for $1 \mathrm{~min}$. The activity was calculated using the extinction coefficient of $3.37 \mathrm{mM}^{-1} \mathrm{~cm}^{-1}$.

Glyoxalase II (EC: 3.1.2.6) activity was determined according to the method of Principato et al. [47] by monitoring the formation of GSH at $412 \mathrm{~nm}$ for $1 \mathrm{~min}$. The reaction mixture contained $100 \mathrm{mM}$ Tris- $\mathrm{HCl}$ buffer $(\mathrm{pH} 7.2)$, $0.2 \mathrm{mM}$ DTNB and $1 \mathrm{mM} S$-D-lactoylglutathione (SLG) in a final volume of $1 \mathrm{~mL}$. The activity was calculated using the extinction coefficient of $13.6 \mathrm{mM}^{-1} \mathrm{~cm}^{-1}$.

2.10. Statistical Analysis. All data obtained were subjected to analysis of variance (ANOVA) and the mean differences were compared by a Duncan's multiple range test (DMRT) using XLSTAT v.2013.5.03 software [48]. Differences at $P<0.05$ were considered significant.

\section{Results}

Upon exposure to salt, stress leaf RWC decreased significantly in both rice varieties when compared to their controls (Figure 1). However, decline in RWC was lower in salt tolerant cultivar BRRI dhan54 as compared to salt sensitive BRRI dhan49. At $150 \mathrm{mM}$ of $\mathrm{NaCl}$ it was decreased by 19 and $12 \%$ in BRRI dhan 49 and BRRI dhan54, respectively over control, while at $300 \mathrm{mM} \mathrm{NaCl}$ the RWC decreased by 29 and $28 \%$ (Figure 1). The application of Pro and GB effectively maintained the RWC in salt stressed seedlings. In BRRI dhan 49, Pro could increase RWC by 16 and $21 \%$ in seedlings exposed to 150 and $300 \mathrm{mM} \mathrm{NaCl}$, respectively, while GB could increase the RWC by 13 and 34\%. In case of BRRI dhan54, the increases were 10 and $20 \%$ at $150 \mathrm{mM} \mathrm{NaCl}$ and 6 and $34 \%$ at $300 \mathrm{mM} \mathrm{NaCl}$ (Figure 1).

Leaf chl contents were decreased markedly upon exposure to salt stress. In salt sensitive BRRI dhan 49 , chl $a$ content decreased by 21 and $31 \%$ at 150 and $300 \mathrm{mM} \mathrm{NaCl}$ while in salt tolerant BRRI dhan54 chl a content decreased by 6 and 20\% only (Figure 2(a)). On the other hand, when the seedlings were supplemented with exogenous Pro and GB chl $a$ content significantly increased in BRRI dhan 49 at any level of salt; however, in BRRI dhan54 the increment was observed at $300 \mathrm{mM} \mathrm{NaCl}$ only (Figure 2(a)). In BRRI dhan 49 , chl $b$ content was decreased by 21 and $31 \%$ at 150 and $300 \mathrm{mM} \mathrm{NaCl}$, while in BRRI dhan54 it was decreased by 6 and 21\%, respectively (Figure 2(b)). Exogenous Pro and GB could maintain chl $b$ content higher compared to the seedlings grown under salt stress. However, the increment was higher in salt sensitive BRRI dhan49 than salt tolerant BRRI dhan54 (Figure 2(b)). In both rice cultivars chl $(a+b)$ content markedly decreased upon exposure to salt stress. In BRRI dhan 49 chl $(a+b)$ content decreased by 20 and $31 \%$ compared to control while in BRRI dhan 54 it decreased by 6 and 21\% (Figure 2(c)). In salt sensitive BRRI dhan 49 exogenous Pro and GB increased the chl $(a+b)$ content in the seedlings exposed to any levels of salt, while in salt tolerant the increase was observed in the seedlings exposed to $300 \mathrm{mM} \mathrm{NaCl}$ only (Figure 2(c)).

Salt stress caused a marked increase in endogenous Pro content in rice seedlings of any variety; however, the increment was higher at salt tolerant BRRI dhan54 compared to salt sensitive BRRI dhan49. In BRRI dhan49 Pro content increased by 52 and $105 \%$ at 150 and $300 \mathrm{mM} \mathrm{NaCl}$, respectively (Figure 3). At the same levels of salt stress, BRRI dhan54 showed 92 and 160\% increase in Pro content compared to control. Importantly, exogenous Pro and GB could also increase the endogenous Pro content further compared to the seedlings exposed to salt without Pro and GB supplementation. However, the comparative increase was higher in salt sensitive BRRI dhan49 than salt tolerant BRRI dhan54 (Figure 3).

The MDA content (indicator of lipid peroxidation) sharply increased at any level of salt stress in both rice varieties. However, the rate on increment was higher in salt sensitive BRRI dhan49. In BRRI dhan49, 150 and $300 \mathrm{mM}$ $\mathrm{NaCl}$ caused 76 and $159 \%$ increase in MDA content while in BRRI dhan54 it was 41 and 95\%, respectively, compared 


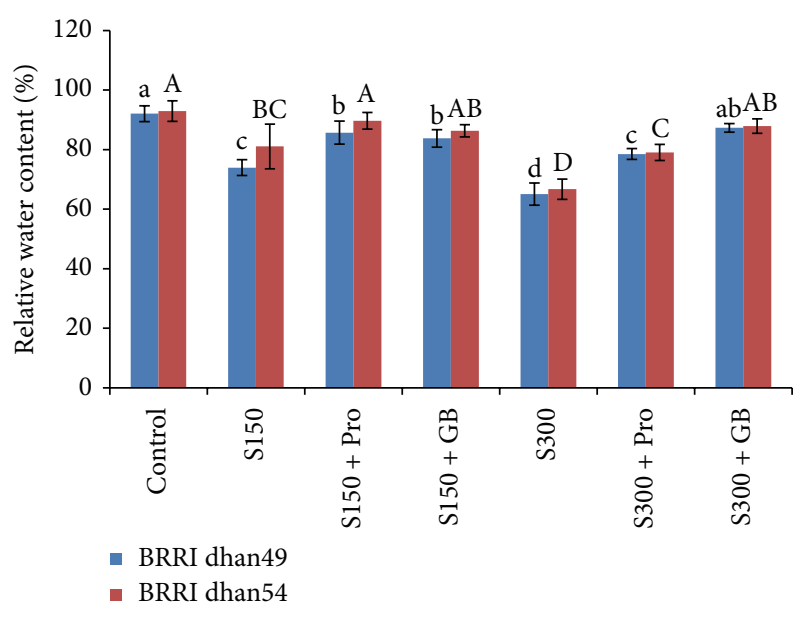

FIGURE 1: Leaf relative water content in salt sensitive and salt tolerant rice seedlings induced by exogenous proline and glycine betaine under salt stress. $S_{150}$ and $S_{300}$ indicate $150 \mathrm{mM} \mathrm{NaCl}$ and $300 \mathrm{mM} \mathrm{NaCl}$, respectively. Pro and GB indicate $5 \mathrm{mM}$ proline and glycine betaine spray, respectively. Mean $( \pm S D)$ was calculated from three replicates for each treatment. Bars with different letters (small letters for BRRI dhan 49 and capital letters for BRRI dhan54) are significantly different at $P \leq 0.05$ applying DMRT.

to control (Figure 4(a)). The seedlings supplemented with Pro and GB could maintain the level of MDA significantly lower compared to the seedlings exposed to salt stress without supplementation (Figure 4(a)).

In our experiment LOX activity was sharply increased by salt stress (Figure $4(\mathrm{~b})$ ). In salt sensitive BRRI dhan 49 the LOX activity was increased by 33 and $67 \%$ at 150 and $300 \mathrm{mM} \mathrm{NaCl}$, respectively, compared to control, while in salt tolerant BRRI dhan54 the activity was 31 and $65 \%$ higher than the control. However, in both of the varieties the activity of LOX was significantly declined in the salt treated seedlings which were supplemented with exogenous Pro and GB (Figure 4(b)).

The levels of $\mathrm{H}_{2} \mathrm{O}_{2}$ also increased noticeably upon exposure to $\mathrm{NaCl}$. In BRRI dhan 49 the $\mathrm{H}_{2} \mathrm{O}_{2}$ content was increased by 35 and $69 \%$ at 150 and $300 \mathrm{mM} \mathrm{NaCl}$, while in BRRI dhan54 it was increased by 32 and $63 \%$, respectively, compared to control (Figure 4(c)). Both Pro and GB could maintain the $\mathrm{H}_{2} \mathrm{O}_{2}$ content lower in salt-stressed seedlings compared to the seedlings grown without Pro or GB supplementation (Figure 4(c)).

Leaf AsA content showed differential responses in two rice varieties when exposed to salt stress. In salt sensitive BRRI dhan 49 salt stress at any level caused marked decrease in AsA content which was 26 and 51\% lower than the control (Figure 5(a)). However, in salt tolerant BRRI dhan54 AsA content increased by $14 \%$ at $150 \mathrm{mM} \mathrm{NaCl}$ stress, while at $300 \mathrm{mM} \mathrm{NaCl}$ it remained unchanged. The seedlings supplemented with exogenous Pro and GB increased the AsA contents in the seedlings of BRRI dhan 49 when exposed to salt stress at any level. However, in BRRI dhan54 such protection was observed at $300 \mathrm{mM} \mathrm{NaCl}$ only (Figure 5(a)).
In salt sensitive BRRI dhan 49 GSH content decreased by 27 and $57 \%$ in the seedlings exposed to 150 and $300 \mathrm{mM}$ $\mathrm{NaCl}$, respectively. On the contrary, BRRI dhan54 showed marked increase in GSH content under salt stress which was 49 and $51 \%$ higher at 150 and $300 \mathrm{mM} \mathrm{NaCl}$, respectively, compared to control (Figure 5(b)). In BRRI dhan49, the seedlings supplemented with Pro and GB could increase GSH content under mild stress $(150 \mathrm{mM} \mathrm{NaCl})$ while no increase was observed in the seedlings grown under $300 \mathrm{mM} \mathrm{NaCl}$. However, in BRRI dhan 54 such protection (increase in GSH content) was observed at any level of salt stress (Figure 5(b)).

The GSSG content in rice seedlings of any variety sharply increased at any level of salt stress. In salt sensitive BRRI dhan 49 the levels were increased by 143 and $224 \%$ at 150 and $300 \mathrm{mM} \mathrm{NaCl}$, respectively. The increase of GSSG was a bit lower in salt tolerant BRRI dhan54 which was 104 and $220 \%$ higher at 150 and $300 \mathrm{mM} \mathrm{NaCl}$ compared to control (Figure 5(c)). Exogenous Pro and GB, on the other hand, maintained the GSSG content significantly lower under salt stress compared to the seedlings grown without Pro and GB supplementation (Figure 5(c)). However, in tolerant variety BRRI dhan54 Pro and GB did not show this protection under mild salt stress $(150 \mathrm{mM})$.

The ratio of GSH/GSSG decreased markedly under salt stress in dose dependent manners and it greatly varied with varieties (Figure 5(d)). In salt sensitive BRRI dhan 49150 and $300 \mathrm{mM} \mathrm{NaCl}$ resulted in 70 and $87 \%$ decrease in GSH/GSSG ration, while in salt tolerant BRRI dhan 54 it decreased by 21 and $53 \%$, respectively, compared to control (Figure 5(d)).

Under salt stress the activity of SOD decreased in salt sensitive variety while it increased in salt tolerant variety (Figure 6(a)). In BRRI dhan 49 the activity of SOD was 24 and $29 \%$ lower than control when treated with 150 and $300 \mathrm{mM}$ $\mathrm{NaCl}$, respectively. On the other hand, the activity was 52 and $38 \%$ higher in BRRI dhan54 at same doses of $\mathrm{NaCl}$. In BRRI dhan49, Pro and GB supplemented salt treated seedlings showed the enhancement of SOD activity. However, in case of BRRI dhan54 slight increase in SOD activity was observed only at $300 \mathrm{mM} \mathrm{NaCl}$ (Figure 6(a)).

Catalase activity showed differential responses in rice seedlings with variable salt tolerance levels and also induced by salt levels (Figure 6(b)). In salt sensitive BRRI dhan49, the activity decreased by any level of salt stress (31 and 55\% lower at 150 and $300 \mathrm{mM} \mathrm{NaCl}$, resp., compared to the control). Salt tolerant BRRI dhan54 showed significant increase in CAT activity under mild stress $(150 \mathrm{mM} \mathrm{NaCl})$, whereas a slight decrease (11\%) was observed at severe stress $(300 \mathrm{mM})$. However, exogenous Pro and GB enhanced the CAT activity in salt-treated seedlings (Figure 6(b)).

Imposition of salt stress of $150 \mathrm{mM}$ significantly increased the APX activity by $40 \%$ in salt sensitive BRRI dhan 49 while in salt tolerant BRRI dhan54 it was increased by $45 \%$ compared to control. Under severe salt stress $(300 \mathrm{mM}$ $\mathrm{NaCl}$ ), APX activity was decreased by $27 \%$ in salt sensitive cultivar but it was increased by $27 \%$ in salt tolerant cultivar (Figure 7(a)). Exogenous Pro and GB supplementation in salt stressed seedlings maintained higher APX activities, compared to salt stress alone, whereas in salt tolerant BRRI dhan54 the activity was always higher than BRRI 


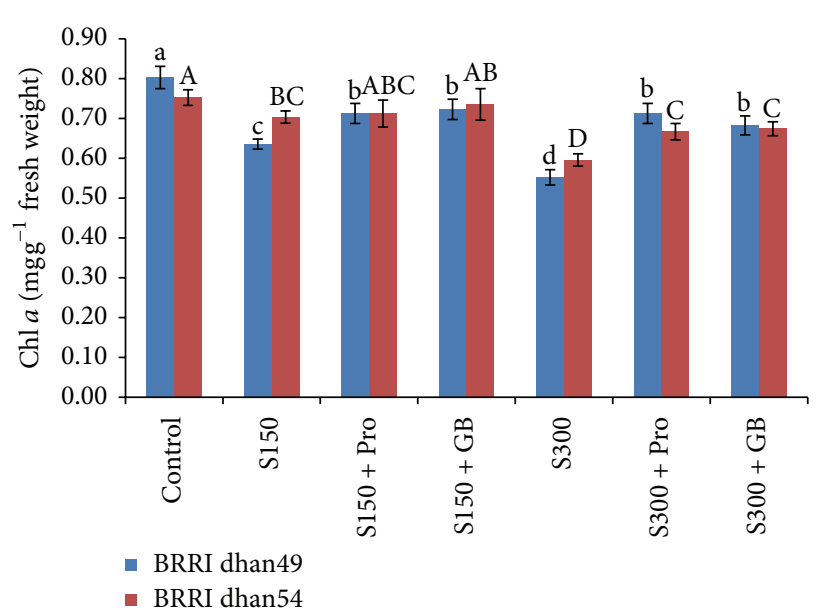

(a)

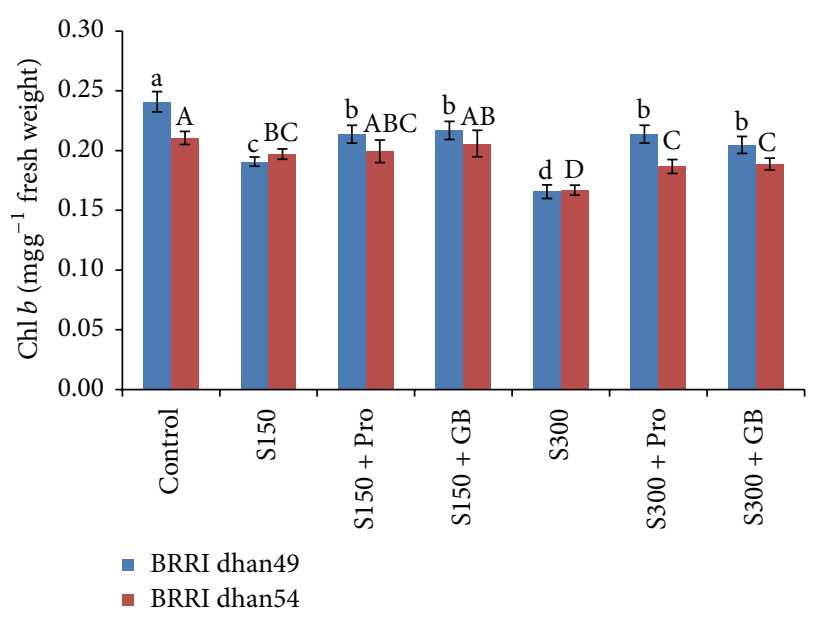

(b)

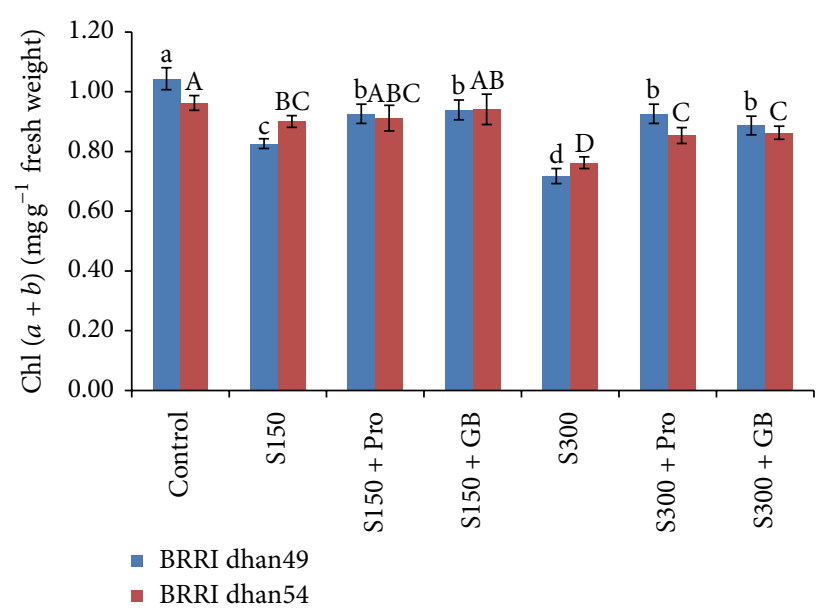

(c)

Figure 2: (a) chl $a$, (b) $\operatorname{chl} b$, and (c) chl $(a+b)$ content in salt sensitive and salt tolerant rice seedlings induced by exogenous proline and glycine betaine under salt stress. $S_{150}$ and $S_{300}$ indicate $150 \mathrm{mM} \mathrm{NaCl}$ and $300 \mathrm{mM} \mathrm{NaCl}$, respectively. Pro and GB indicate $5 \mathrm{mM}$ proline and glycine betaine spray, respectively. Mean $( \pm S D)$ was calculated from three replicates for each treatment. Bars with different letters (small letters for BRRI dhan 49 and capital letters for BRRI dhan54) are significantly different at $P \leq 0.05$ applying DMRT.

dhan 49 (Figure 7(a)). Addition of Pro with $150 \mathrm{mM}$ salt stress increased APX activities in BRRI dhan 49 by $29 \%$ and in BRRI dhan54 it was as high as the stress condition; its activities were increased by 46 and $17 \%$ under severe salt stress in those two cultivars (compared to salt stress alone). The GB addition also increased its activity in all the cases except for BRRI dhan 54 in severe stress (Figure 7(a)).

Salt stress at any level decreased the MDHAR activity in salt sensitive BRRI dhan 49 which were 19 and $24 \%$ lower at 150 and $300 \mathrm{mM} \mathrm{NaCl}$, respectively, compared to control (Figure 7(b)). In contrast, MDHAR activity in BRRI dhan54 increased by $23 \%$ at $150 \mathrm{mM} \mathrm{NaCl}$, while it was unaffected under severe salt stress $(300 \mathrm{mM} \mathrm{NaCl})$. Exogenous Pro and GB addition under any levels of salt stress significantly increased MDHAR activities irrespective of cultivars (Figure 7(b)).

Salt stress caused a marked decrease in DHAR activity of BRRI dhan 49 seedlings at any level of stress; however, in salt tolerant BRRI dhan 54 its activity only decreased in severe stress ( $300 \mathrm{mM} \mathrm{NaCl}$ ). In BRRI dhan49, due to exogenous Pro application DHAR activities were increased by 35 and $38 \%$ at 150 and $300 \mathrm{mM} \mathrm{NaCl}$, respectively. In BRRI dhan54, exogenous Pro supplemented seedlings showed increased DHAR activities by 17 and $31 \%$ at 150 and $300 \mathrm{mM} \mathrm{NaCl}$, respectively, compared to salt stress alone (Figure 7(c)). Similarly, in GB supplemented BRRI dhan 49 seedlings, DHAR activities were increased by 35 and 31\% and its activities increased by 16 and $17 \%$ in BRRI dhan 54 at 150 and $300 \mathrm{mM} \mathrm{NaCl}$, respectively, compared to salt stress alone (Figure 7(c)).

The GR activity showed different responses in two rice varieties in salt stress. Compared to control, the salt sensitive BRRI dhan 49 had decreased GR activities of 26 and $25 \%$ in exposure to 150 and $300 \mathrm{mM} \mathrm{NaCl}$, respectively (Figure 7(d)). In opposition, salt tolerant BRRI dhan54 had significantly higher GR activities of 33 and 23\% with 150 and $300 \mathrm{mM}$ $\mathrm{NaCl}$, respectively. Nonetheless, exogenous Pro and GB 


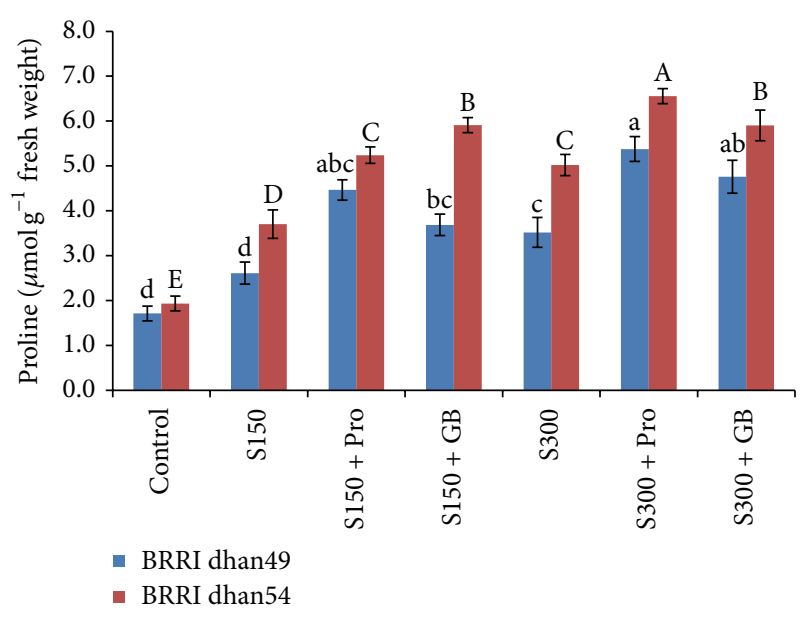

FIgUre 3: Proline content in salt sensitive and salt tolerant rice seedlings induced by exogenous proline and glycine betaine under salt stress. $S_{150}$ and $S_{300}$ indicate $150 \mathrm{mM} \mathrm{NaCl}$ and $300 \mathrm{mM} \mathrm{NaCl}$, respectively. Pro and GB indicate $5 \mathrm{mM}$ proline and glycine betaine spray, respectively. Mean $( \pm S D)$ was calculated from three replicates for each treatment. Bars with different letters (small letters for BRRI dhan 49 and capital letters for BRRI dhan54) are significantly different at $P \leq 0.05$ applying DMRT.

enhanced its activity further in both sensitive and tolerant varieties irrespective of salt doses, compared to the activity in the seedlings exposed to salt stress alone (Figure 7(d)).

Salt stresses of any level decreased GPX activity in both salt sensitive and tolerant cultivar, except that mid stress increased GPX activity in BRRI dhan54, compared to control treatment (Figure 8(a)). Compared to 150 and $300 \mathrm{mM}$ salt stress alone, exogenous Pro and GB supplementation increased GPX activity of BRRI dhan 49 by 18 and 25\%, respectively. In BRRI dhan54 the GPX activity was unaffected by either Pro or GB application (Figure 8(a)). But GPX activity of both salt sensitive and tolerant cultivars was improved significantly by Pro or GB application under severe salt stress $(300 \mathrm{mM})$.

The activity of GST sharply increased in all rice seedlings induced by all levels of salt stress although its activity was slightly higher in salt tolerant BRRI dhan54 (Figure 8(b)). In BRRI dhan49, Pro addition with 150 and $300 \mathrm{mM} \mathrm{NaCl}$ resulted in 15 and 24\% increases in GST activities, compared to salt stresses alone, while in BRRI dhan54 its activity did not increased further by exogenous application of Pro. Under 150 and $300 \mathrm{mM} \mathrm{NaCl}$, GB increased GST activity of BRRI dhan 49 by 20 and 19\%, respectively. In BRRI dhan54, exogenous GB addition did not increase GST activity under $150 \mathrm{mM} \mathrm{NaCl}$ treatment, while it decreased under $300 \mathrm{mM}$ $\mathrm{NaCl}$ (Figure 8(b)).

The activity of Gly I was different in rice varieties differing in salt tolerance. In salt sensitive BRRI dhan49, the activity of Gly decreased by 25 and $41 \%$ upon exposure to 150 and $300 \mathrm{mM} \mathrm{NaCl}$, respectively, compared to control (Figure 9(a)). On the contrary, salt tolerant BRRI dhan54 showed 29 and $17 \%$ increase in Gly I activity when treated with 150 and $300 \mathrm{mM} \mathrm{NaCl}$, respectively. However, in both of the varieties exogenous Pro and GB enhanced the activity of Gly I further compared to the activity in the seedlings exposed to salt with Pro and GB supplementation (Figure 9(b)).

For salt sensitive BRRI dhan 49 the activity of Gly II slightly increased (by $24 \%$ ) at $150 \mathrm{mM} \mathrm{NaCl}$, while it remained unaffected at $300 \mathrm{mM} \mathrm{NaCl}$. However, in salt tolerant BRRI dhan54 treatment with 150 and $300 \mathrm{mM}$ $\mathrm{NaCl}$ resulted in 33 and $45 \%$ increase in Gly II activity as compared to control (Figure 9(b)). For BRRI dhan49 Pro and GB supplementation could enhance the Gly II activity at any level of salt (33 and $44 \%$ at 150 and $300 \mathrm{mM} \mathrm{NaCl}$, resp.), while in BRRI dhan54 further upregulation of Gly II activity was observed in seedlings grown under $150 \mathrm{mM} \mathrm{NaCl}$ (Figure 9(b)).

\section{Discussion}

Salt stress causes several biochemical and physiological alterations such as decrease in water content in tissues, decline in photosynthetic pigments, and oxidative stress. Salt stress often caused accelerated generation and reactions of ROS including ${ }^{1} \mathrm{O}_{2}, \mathrm{O}_{2}{ }^{--}, \mathrm{H}_{2} \mathrm{O}_{2}$, and $\mathrm{OH}^{\bullet}$ leading to oxidative stress [2]. However, components of antioxidant defense systems in plants work in concert with control the cascades of uncontrolled oxidation and protect plant cells from oxidative damage by scavenging ROS $[2,18]$. But in some cases such as severe stress condition these defense systems are required to be upregulated more than their normal limit. Compatible solutes like Pro and GB were found to protect the plants from salt-induced damages due to their role of osmoprotection and antioxidant defense as well. Several reports indicated that enhanced accumulations of Pro and GB are positively correlated with higher tolerance to salt stress [27, 28, 49].

Since salt stress causes osmotic stress, the decline in RWC is a common phenomenon in plants growth under salinity and hence RWC is considered as a potent indicator for evaluating plants for tolerance to salt stress. In our study, salt stress led to a significant decrease of RWC in rice leaves irrespective to $\mathrm{NaCl}$ concentration and the rice cultivars (Figure 1). Similar decrease in RWC due to salt stress was reported earlier [50,51]. Decrease in RWC was due to loss of turgor that results in limited water availability for cell extension processes [52]. However, when salt treated seedlings were supplemented with Pro or GB they showed enhanced RWC which was due to the retention in water in their tissue (Figure 1). The enhanced water content in plants due to exogenous application was also observed by other researchers $[22,53,54]$. In BRRI dhan54 the RWC was slightly higher than BRRI dhan 49 which was due to its better tolerance.

In our experiment salt caused reduction in chl content, namely, chl $a$, chl $b$, and chl $(a+b)$, in both rice varieties. However, the reduction was higher in salt sensitive BRRI dhan 49 (Figures 2(a)-2(c)). Salt stress often causes alteration in photosynthetic pigment biosynthesis [55]. Similar decrease in chl content was observed by Amirjani [56] in rice. However, exogenous application of Pro and GB in salt treated 


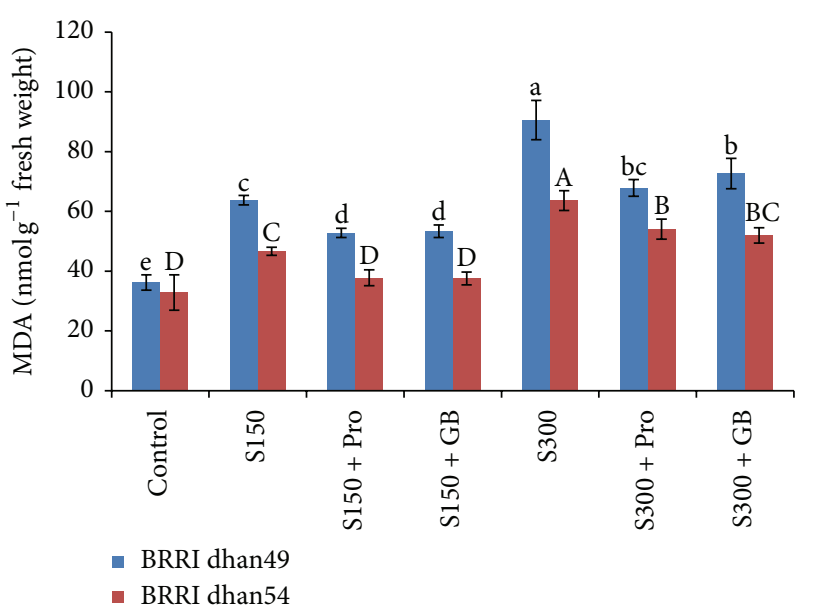

(a)

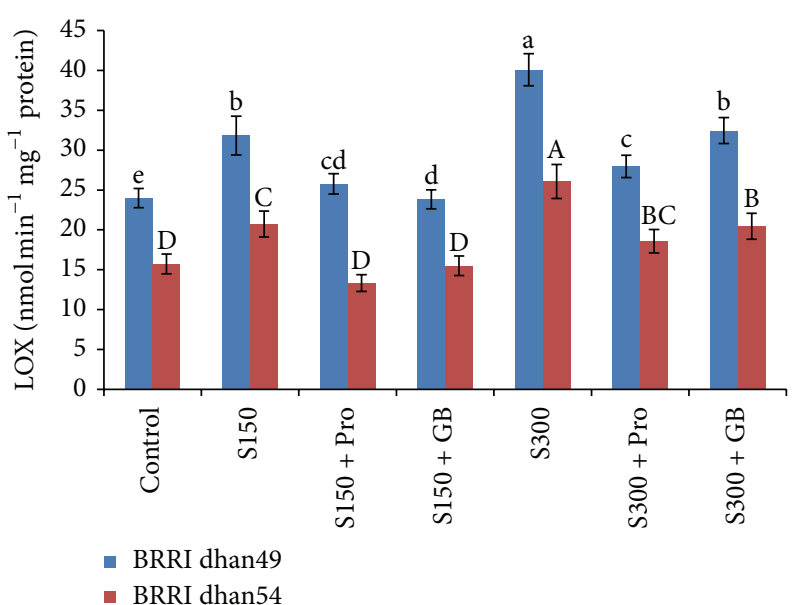

(b)

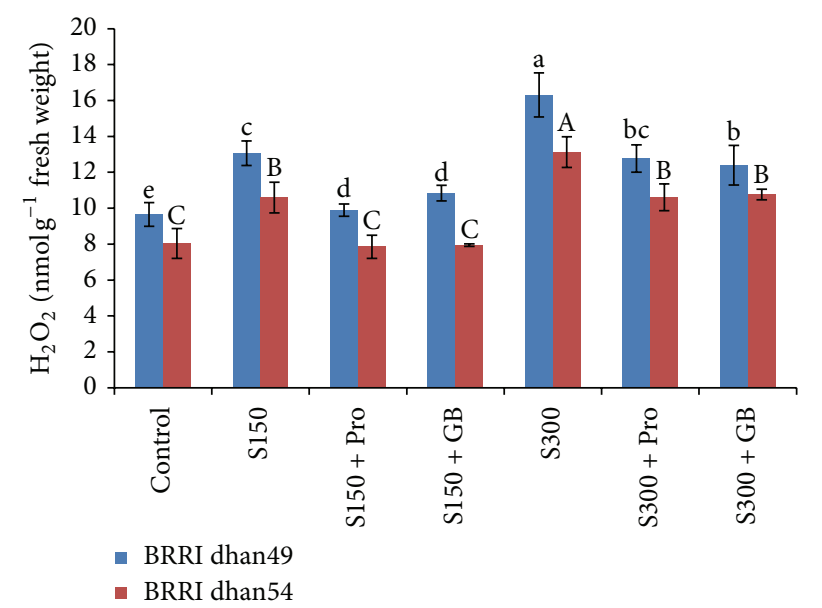

(c)

Figure 4: (a) MDA content, (b) LOX activity, and (c) $\mathrm{H}_{2} \mathrm{O}_{2}$ content in salt sensitive and salt tolerant rice seedlings induced by exogenous proline and glycine betaine under salt stress. $S_{150}$ and $S_{300}$ indicate $150 \mathrm{mM} \mathrm{NaCl}$ and $300 \mathrm{mM} \mathrm{NaCl}$, respectively. Pro and GB indicate $5 \mathrm{mM}$ proline and glycine betaine spray, respectively. Mean $( \pm S D)$ was calculated from three replicates for each treatment. Bars with different letters (small letters for BRRI dhan 49 and capital letters for BRRI dhan54) are significantly different at $P \leq 0.05$ applying DMRT.

seedlings could elevate the chl content which might be due to the higher biosynthesis of the pigment. These results are in agreement with Raza et al. [27] and Sakr et al. [30].

Accumulation of Pro is often suggested as a selection criterion for the stress tolerance of most plant species [22, 24]. In our experiment both rice varieties showed enhanced Proaccumulation under any level of salt stress (Figure 3). However, BRRI dhan54 showed comparatively higher Pro content than BRRI dhan 49 due to its adaptive features of higher tolerance. Importantly, exogenous application of Pro and GB in stressed plants further enhanced the endogenous Pro content and in every case the effect of Pro was higher than GB (Figure 3). More importantly in salt tolerant BRRI dhan54 the enhancement due to exogenous Pro and GB was slightly lower than BRRI dhan 49 which was probably due to the fact that this variety has got the enhanced level of Pro due to its natural tolerance capacity. Pro and GB-induced counteraction of salt stress due to enhanced Pro content was reported earlier in different plants $[27,30]$.

Lipid peroxidation is a well-known index for determining the extent of oxidative stress because increased MDA content has been found to be highly correlated with oxidative damages induced by various abiotic stresses including salinity [57]. Hydrogen peroxide is a toxic compound which is injurious to the cell and excessive accumulation of $\mathrm{H}_{2} \mathrm{O}_{2}$ is one of the indicators of oxidative stress [2]. In our experiment both MDA and $\mathrm{H}_{2} \mathrm{O}_{2}$ were found to be increased under salt stress which was in agreement with several previous reports $[2,3,58-60]$. On the contrary, salt treated seedlings supplemented with exogenous Pro and GB showed lower MDA and $\mathrm{H}_{2} \mathrm{O}_{2}$ contents ((Figures 4(a) and 4(c)) which was due to their higher antioxidant defense system. Exogenous Pro and GB-induced upregulation of antioxidant defense and concomitant decrease in MDA and $\mathrm{H}_{2} \mathrm{O}_{2}$ content was 


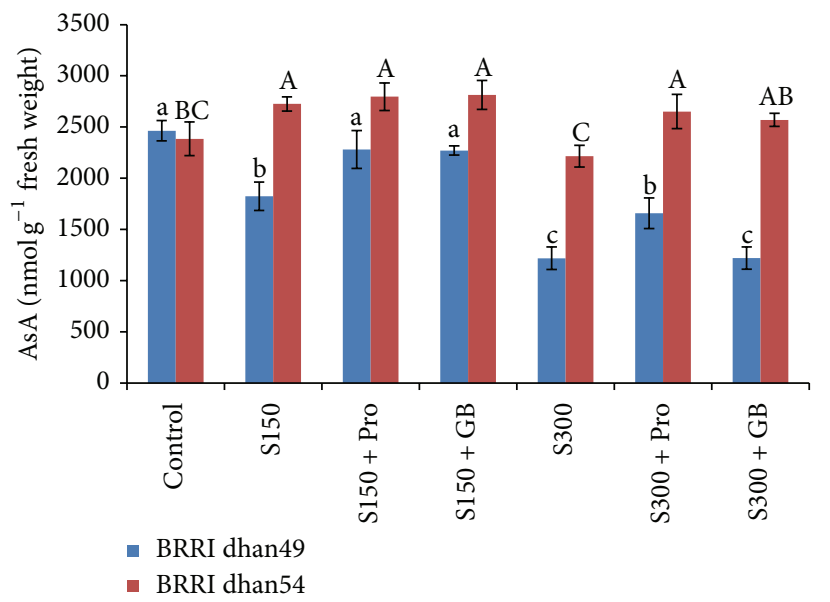

(a)

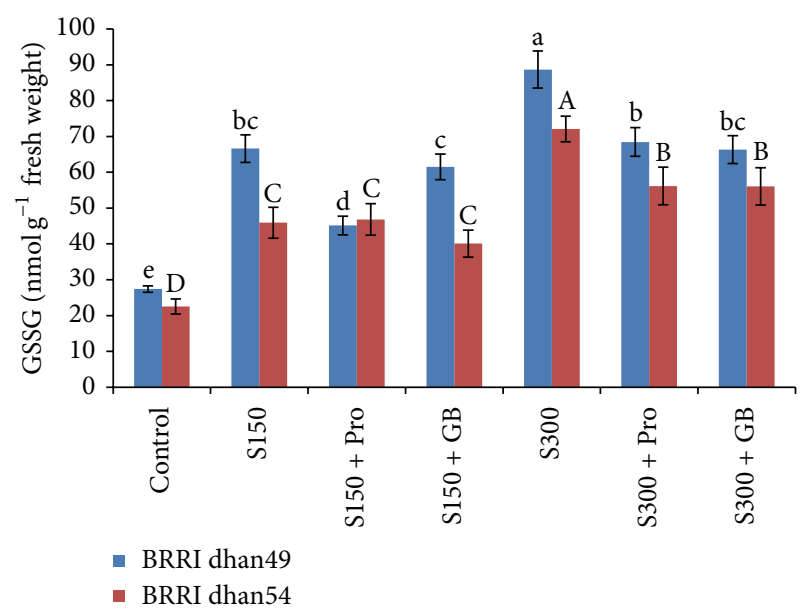

(c)

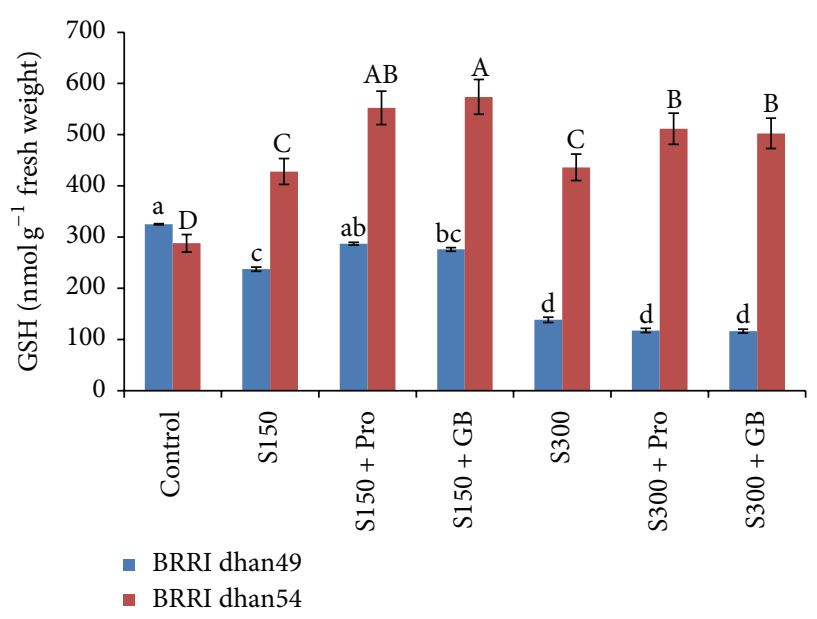

(b)

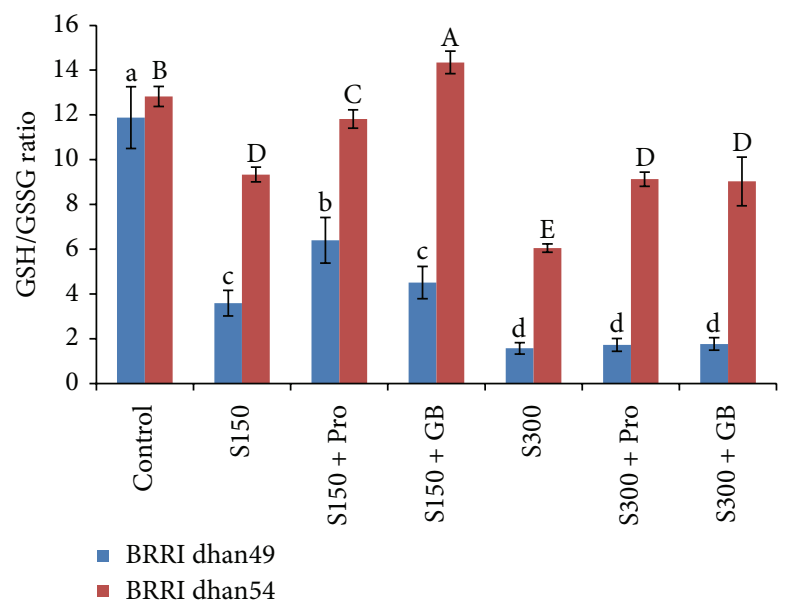

(d)

Figure 5: (a) AsA content, (b) GSH content, (c) GSSG content, and (d) GSH/GSSG ratio in salt sensitive and salt tolerant rice seedlings induced by exogenous proline and glycine betaine under salt stress. $S_{150}$ and $S_{300}$ indicate $150 \mathrm{mM} \mathrm{NaCl}$ and $300 \mathrm{mM} \mathrm{NaCl}$, respectively. Pro and GB indicate $5 \mathrm{mM}$ proline and glycine betaine spray, respectively. Mean $( \pm \mathrm{SD})$ was calculated from three replicates for each treatment. Bars with different letters (small letters for BRRI dhan 49 and capital letters for BRRI dhan54) are significantly different at $P \leq 0.05$ applying DMRT.

observed in many plant species including rice [49, 61, 62]. In our experiment LOX activity was sharply increased in salt treated seedlings in both rice varieties (Figure 4(b)). This higher activity of LOX was assumed as reasons for increased lipid peroxidation that caused oxidation of polyunsaturated fatty acids as reported in many plant studies [63-65]. This result was correlated with higher MDA content of those seedlings grown under salt stress. However, exogenous Pro and GB protected the seedlings by decreasing lipid peroxidation which was reflected with the lower activity of LOX [65].

AsA and GSH have vital roles in development of plant stress tolerance to adverse environmental conditions [66, 67]. Increased AsA or GSH content can effectively reduce ROS produced under stress conditions including salt stress and thus prevents oxidative stress [68]. In the present study, we examined the performance of salt tolerance and salt sensitive rice cultivars against different salinity levels and we also examined how they are protected from salt stress by exogenous Pro or GB application. The result was interesting indeed. Because it was observed that under mild salt stress condition AsA level of salt sensitive BRRI dhan 49 was reduced whereas the AsA level of BRRI dhan54 was increased (Figure 5(a)). Severe salt stress also reduced the AsA level of salt sensitive cultivar and this stress maintained the AsA level of tolerant cultivar similar to the control. This result is correlated to MDHAR and DHAR activities which regulate the recycling of AsA within the cell. From Figure 7, it is clear that when the MDHAR or DHAR activity was reduced in salt sensitive BRRI dhan49, then its AsA levels were reduced irrespective of different salt doses. The higher MDHAR and DHAR activities of salt tolerant BRRI dhan54 were also related to its AsA levels (Figures 5(a), 7(b), and 7(c)). Exogenous Pro and GB supplementation significantly enhanced MDHAR and DHAR activities and subsequently improved AsA levels of 


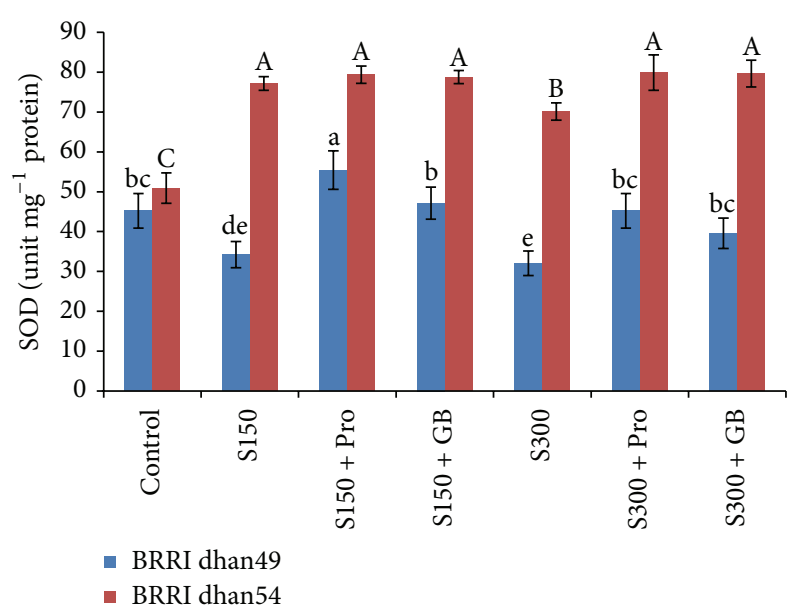

(a)

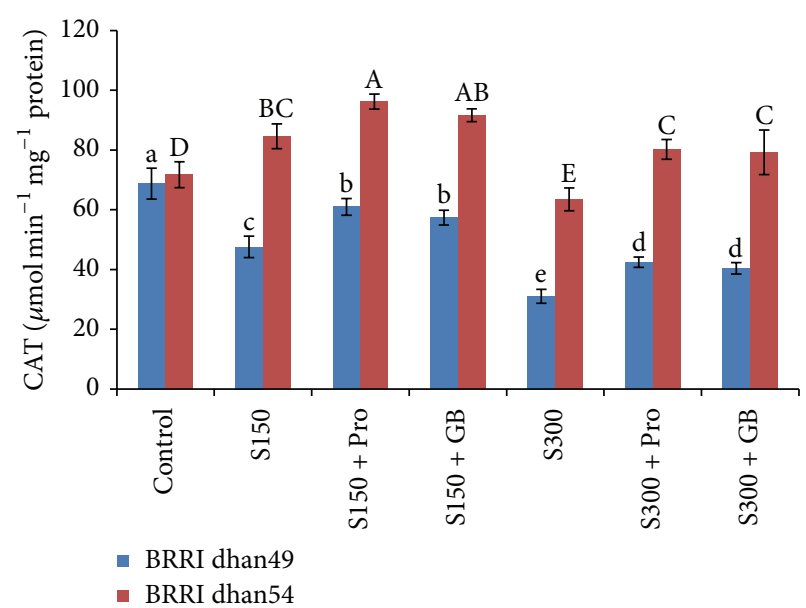

(b)

FIGURE 6: Activities of SOD (a) and CAT (b) in salt sensitive and salt tolerant rice seedlings induced by exogenous proline and glycine betaine under salt stress. $\mathrm{S}_{150}$ and $\mathrm{S}_{300}$ indicate $150 \mathrm{mM} \mathrm{NaCl}$ and $300 \mathrm{mM} \mathrm{NaCl}$, respectively. Pro and GB indicate $5 \mathrm{mM}$ proline and glycine betaine spray, respectively. Mean $( \pm S D)$ was calculated from three replicates for each treatment. Bars with different letters (small letters for BRRI dhan 49 and capital letters for BRRI dhan54) are significantly different at $P \leq 0.05$ applying DMRT.

both cultivars under mild stress. At severe stress, Pro or GB enhanced the activities of two enzymes in both cultivars and tolerant cultivar AsA level was improved in all cases. But GB could not improve the AsA level of sensitive cultivar under severe stress. The similar results regarding modulation of AsA pool and its related enzymes by exogenous Pro and GB under salt stress was previously reported [28, 29]. They also mentioned Pro as more efficient protectant than GB. The GSH/GSSG ratio is indicative of the cellular redox balance that plays vital roles in scavenging ROS, maintains balance state of AsA-GSG cycle, and acts as signal during stress and numerous studies proved its protective roles under stress conditions $[10,18,69]$. In the present study, drastic reduction of GSH contents and increased levels of GSH were observed under salt stress for salt sensitive and salt tolerant cultivars, respectively (Figure 5(c)). Salt stress increased the GSSG levels in both cultivars. These combined rendered the higher GSH/GSSG ratio for tolerant cultivar BRRI dhan54 and reduced GSH/GSSG in sensitive BRRI dhan 49 (Figure 5(d)). Exogenous Pro and GB improved GSH and GSH/GSSG ratio in tolerant cultivar in all salinity levels. But in sensitive cultivar these parameters were only improved by Pro under mild salt stress. More efficiency of Pro as compared to GB under salt stress was previously reported $[28,29]$. This increased GSH content might be due to the significant increase in GR activities (Figure 7(d)) and higher GSH biosynthesis [18]. Previously higher reduced glutathione GSH content and GSH/GSSG ratio proved the existence of reduced redox state in cells by exogenous Pro and GB treatment $[28,70]$. Previous research findings also expressed that higher levels of GSH or GSH/GSSG ratio induced by exogenous Pro and GB in turn helps to maintain the activity of GSH dependent antioxidant enzymes such as GPX, GR, and GST to scavenge ROS from cell $[28,70,71]$. These findings supported the results of our study which are mostly factual for the salt tolerant BRRI dhan54 and in some cases for the sensitive BRRI dhan 49 .

Salt stress-induced excess generation of ROS and subsequent enhanced activities of many antioxidant enzymes during salt stress have been reported in many plant species. Importantly, the activities of antioxidant enzymes of salt tolerant genotypes are upregulated under salt stress where salt sensitive species failed to do so $[2,4,72]$. In our experiment antioxidant enzymes responded differently in two rice varieties grown under two levels of salt stress. Exogenous application of Pro and GB also showed their protective effect differently in those varieties. Superoxide dismutase is the first line of antioxidant enzyme that removes $\mathrm{O}_{2}{ }^{--}$by catalyzing its dismutation, one $\mathrm{O}_{2}{ }^{--}$being reduced to $\mathrm{H}_{2} \mathrm{O}_{2}$ and another oxidized to $\mathrm{O}_{2}$ [4]. The enhanced activity of SODs minimizes abiotic oxidative stress and has a significant role in the adaptation of a plant to stressed environments [4]. In our experiment salt stress downregulated the SOD activity in salt sensitive BRRI dhan 49 while it clearly upregulated in salt tolerant BRRI dhan54. However, Pro and GB supplementation could enhance the activity further which indicated its role in ROS detoxification (Figure 6(a)). Catalase is a potential enzyme which has higher turnover rate and is capable to dismutase two molecules of $\mathrm{H}_{2} \mathrm{O}_{2}$ to water and oxygen and thus is considered as an efficient ROS detoxifier [4]. There are plenty of reports on the changes in CAT activity or expression and those supported the notion that CAT is the most efficient $\mathrm{H}_{2} \mathrm{O}_{2}$ scavenging enzyme [4, 73]. In our experiment, salt sensitive BRRI dhan 49 showed decline in CAT activity at any level of $\mathrm{NaCl}$ which might be due to ineffective enzyme synthesis or change in assembly of enzyme subunits (Figure 6(b)) $[74,75]$. On the contrary, in salt tolerant BRRI dhan54 the activity slightly increased 


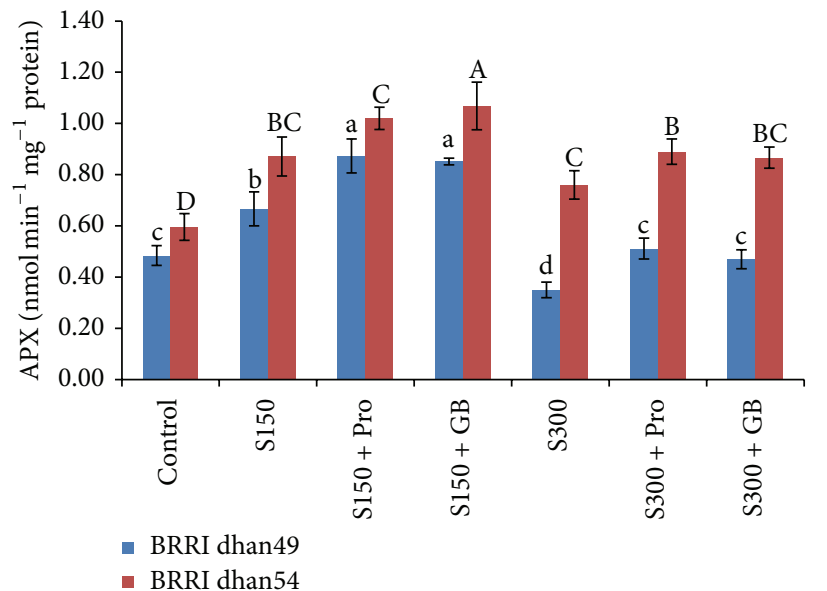

(a)

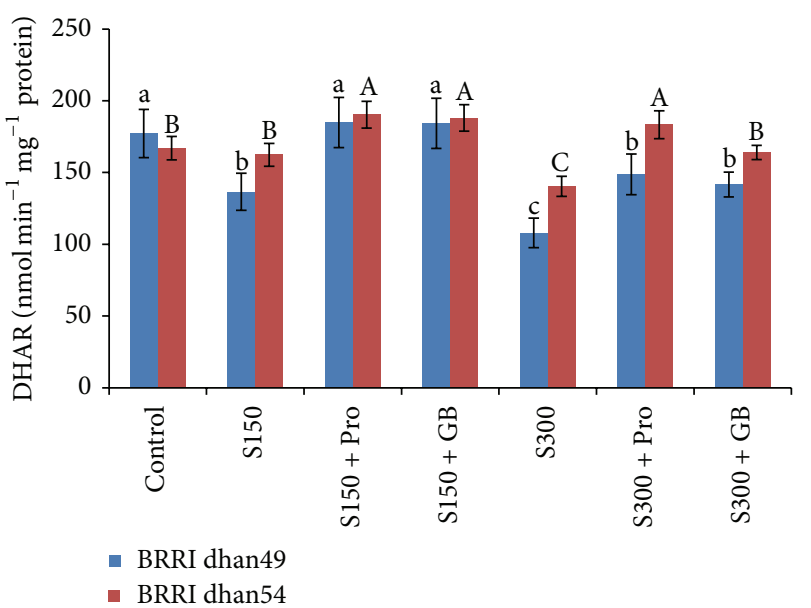

(c)

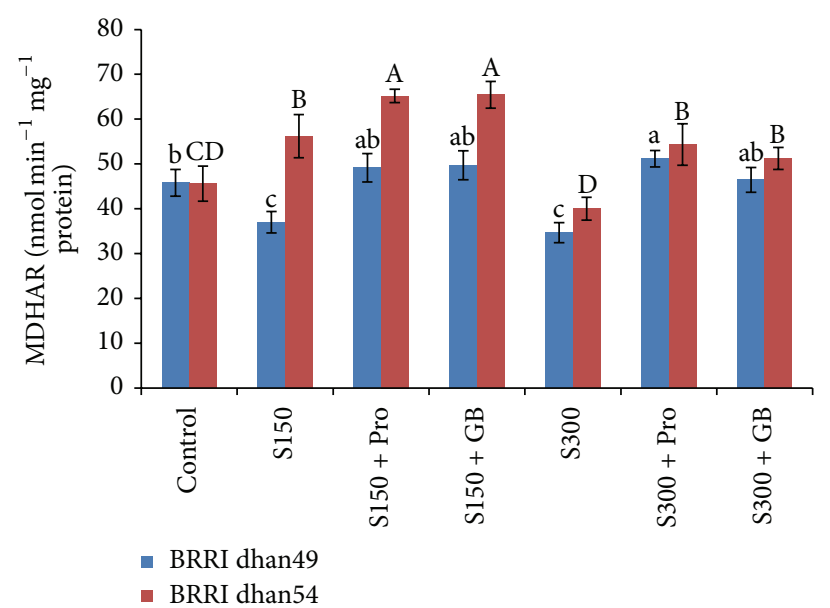

(b)

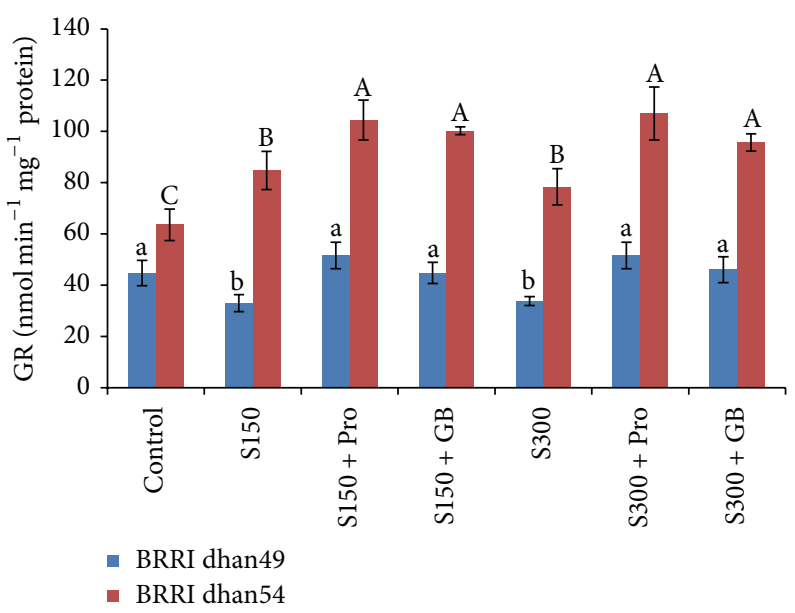

(d)

Figure 7: Activities of APX (a), MDHAR (b), DHAR (c), and GR (d) in salt sensitive and salt tolerant rice seedlings induced by exogenous proline and glycine betaine under salt stress. $S_{150}$ and $S_{300}$ indicate $150 \mathrm{mM} \mathrm{NaCl}$ and $300 \mathrm{mM} \mathrm{NaCl}$, respectively. Pro and GB indicate $5 \mathrm{mM}$ proline and glycine betaine spray, respectively. Mean $( \pm S D)$ was calculated from three replicates for each treatment. Bars with different letters (small letters for BRRI dhan 49 and capital letters for BRRI dhan54) are significantly different at $P \leq 0.05$ applying DMRT.

under mild salt stress $(150 \mathrm{mM} \mathrm{NaCl})$ but decreased under severe stress $(300 \mathrm{mM} \mathrm{NaCl})$. This trend was supported by earlier reports $[58,76,77]$. However, the activity of CAT in the presence of Pro and GB under salt treatment was much higher than those under salt treatment without Pro and GB which suggest a unambiguous role of Pro and GB in scavenging $\mathrm{H}_{2} \mathrm{O}_{2}$ under salt stress. Similar effects were also observed in several recent studies [28, 31, 49, 78].

The four enzymes of AsA-GSH, namely, APX, MDHAR, DHAR, and GR, are vital for antioxidant defense because they are involved in maintaining the AsA and GSH pool. In our experiment APX activity increased in both rice varieties subjected to salt stress and exogenous Pro and GB enhanced the activity further which indicated the $\mathrm{H}_{2} \mathrm{O}_{2}$ scavenging role of Pro and GB (Figure 7(a)). This result was in agreement with other findings $[6,25,49]$. MDHAR and DHAR are two important enzymes related to the regeneration of AsA which is a strong antioxidant. Both enzymes are equally important in regulating AsA level and its redox state under oxidative stress condition [79-81]. The activity of MDHAR and DHAR clearly decreased in salt sensitive BRRI dhan 49 treated with $\mathrm{NaCl}$. However, in salt tolerant BRRI dhan54 the activity increased or remained unchanged depending on the salt concentration (Figures 7(b) and 7(c)). Decrease of MDHAR and DHAR activity under salt stress was also reported in our earlier studies [2, 3]. Exogenous Pro and GB supplemented seedlings, on the other hand, enhanced the activity in both varieties which helped the plants in efficient regeneration of AsA (Figure 5(a)). Glutathione reductase is another important enzyme of AsA-GSH cycle which is important for maintaining high ratio of GSH/GSSG in plant cells, also necessary for accelerating the $\mathrm{H}_{2} \mathrm{O}_{2}$ scavenging $[82,83]$. In salt sensitive BRRI dhan 49 the activity of GR declined under salt stress in dose dependent manners but in salt tolerant BRRI dhan54 it declined only at $300 \mathrm{mM}$ $\mathrm{NaCl}$ (Figure 7(d)). Higher activity of GR in stress tolerant 


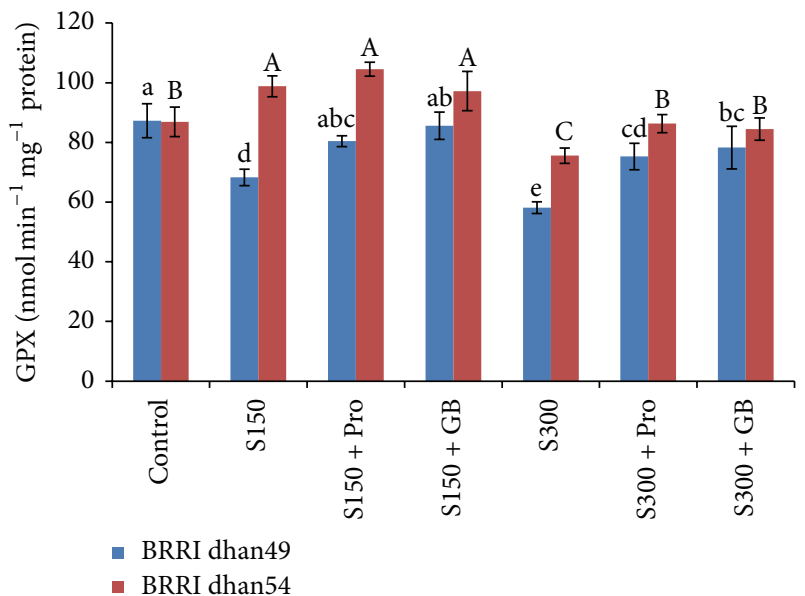

(a)

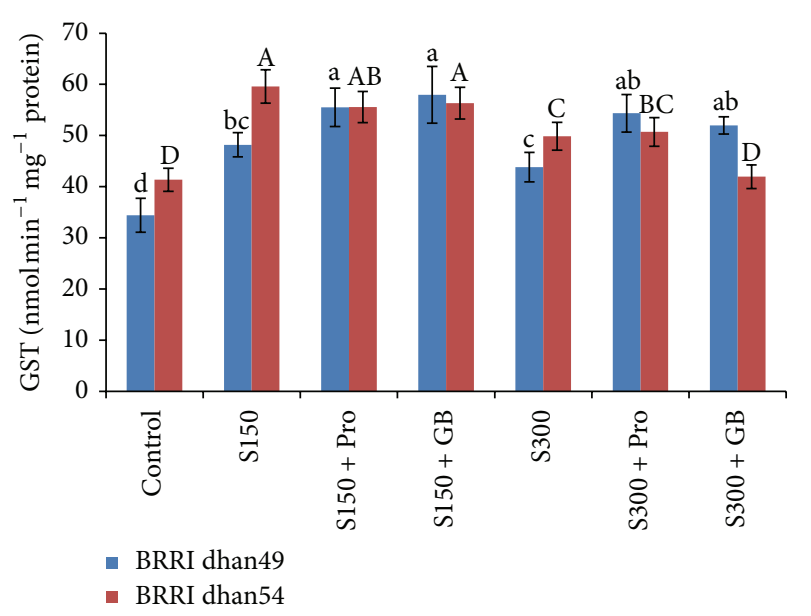

(b)

FIGURE 8: Activities of GPX (a) and GST (b) in salt sensitive and salt tolerant rice seedlings induced by exogenous proline and glycine betaine under salt stress. $S_{150}$ and $S_{300}$ indicate $150 \mathrm{mM} \mathrm{NaCl}$ and $300 \mathrm{mM} \mathrm{NaCl}$, respectively. Pro and GB indicate $5 \mathrm{mM}$ proline and glycine betaine spray, respectively. Mean $( \pm S D)$ was calculated from three replicates for each treatment. Bars with different letters (small letters for BRRI dhan 49 and capital letters for BRRI dhan54) are significantly different at $P \leq 0.05$ applying DMRT.

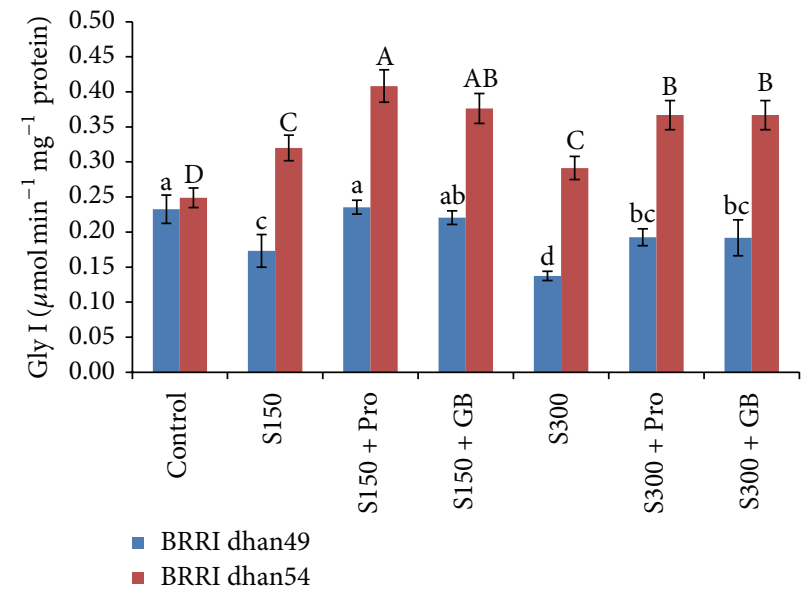

(a)

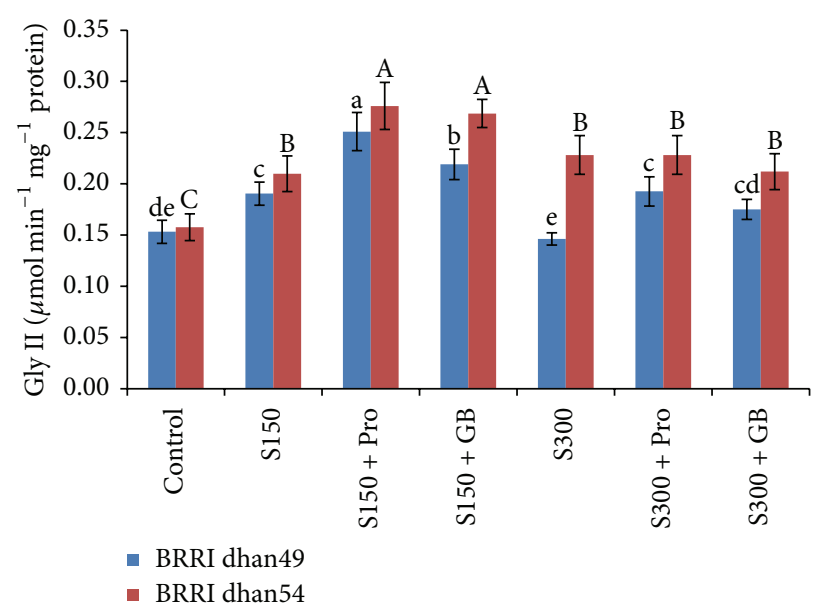

(b)

FIGURE 9: Activities of Gly I (a) and Gly II (b) in salt sensitive and salt tolerant rice seedlings induced by exogenous proline and glycine betaine under salt stress. $S_{150}$ and $S_{300}$ indicate $150 \mathrm{mM} \mathrm{NaCl}$ and $300 \mathrm{mM} \mathrm{NaCl}$, respectively. Pro and GB indicate $5 \mathrm{mM}$ proline and glycine betaine spray, respectively. Mean $( \pm S D)$ was calculated from three replicates for each treatment. Bars with different letters (small letters for BRRI dhan 49 and capital letters for BRRI dhan54) are significantly different at $P \leq 0.05$ applying DMRT.

plants was observed in several studies $[76,84]$. However, in both rice varieties, supplementation of Pro and GB in salt treated seedlings showed enhanced activities of GR which could maintain a high GSH pool (Figures 5(b) and 7(d)). Our results were corroborated with other recent findings where exogenous Pro and GB upregulated the GR activity under salt stress $[15,25,28]$.

The GPX is another vital enzyme of antioxidant defense system and due to substrate specifications and stronger affinity for $\mathrm{H}_{2} \mathrm{O}_{2}$ it can efficiently scavenge, especially, $\mathrm{H}_{2} \mathrm{O}_{2}$ and thus provide protection against stress $[4,85]$. In our experiment salt tolerant variety showed higher activities of GPX compared to salt sensitive variety which was due to an increased synthesis of the enzymes or an increased activation of constitutive enzyme pools (Figure 8(a)). In salt sensitive variety GPX activity declined at any level of salt stress. This indicates inefficient detoxification of ROS in salt sensitive variety (BRRI dhan49). Differential response of GPX activity in salt sensitive and tolerant varieties was reported in many plant studies $[2,3,86]$. However, in salt sensitive variety exogenous Pro and GB upregulated the activity of GR at any level of stress. In contrary, in salt tolerant variety (BRRI 
dhan54) Pro and GB supplemented seedlings showed further increase in GR activity only at severe stress which indicates that under mild stress the activity was well enough to scavenge the excess $\mathrm{H}_{2} \mathrm{O}_{2}$ (Figures 8(a) and 4(c)). It is interesting that GST activity increased sharply in both of the rice varieties exposed to $\mathrm{NaCl}$. Although the primary role of this enzyme has been assigned to the detoxification of xenobiotics, it has also been shown to exhibit antioxidant activity [4]. Plant GSTs are also associated with responses to various forms of abiotic stress $[45,87]$ and stress tolerance is often correlated with enhanced activity of GST [4]. In both rice varieties of our experiment, GST activity markedly increased under salt stress where comparatively higher activity was observed in salt tolerant BRRI dhan54 (Figure 8(b)). Interestingly, exogenous Pro and GB only resulted in further enhancement of GST activity in BRRI dhan 49 only which indicates that the salt tolerant BRRI dhan54 has already got enough capacity to detoxify $\mathrm{H}_{2} \mathrm{O}_{2}$ (Figures $8(\mathrm{~b})$ and $4(\mathrm{c})$ ). Our results are partially supported by Hoque et al. [29].

Glyoxalase system consisting of Gly I and Gly II enzymes effectively detoxify MG in two-step reactions where GSH acts as a cofactor. In first step, Gly I catalyzes the formation of SD-lactoylglutathione (SLG) from the hemithioacetal formed nonenzymatically from MG and GSH. In second step, Gly II catalyzes the hydrolysis of SLG to regenerate GSH and release D-lactate $[17,88]$. Effective glyoxalase system converts MG to D-lactate and at the same time it recycles GSH properly $[2,3]$. Several studies proved that efficient glyoxalase system not only detoxifies $M G$, but also improves stress tolerance $[10,18]$. Different levels of salt stresses significantly reduced Gly I activities in salt sensitive BRRI dhan49. Decrease in Gly I activity under salt stress was also reported previously $[2,89]$. On the contrary those stresses enhancing Gly I activity in salt tolerant BRRI dhan54 cultivar might be an indication of its better tolerance capacity. Moreover, exogenous Pro and GB supplementation with salt media improving Gly I activity in two cultivars in different stress conditions proves the enhanced tolerance level induced by Pro and GB (Figure 9(a)). After salt exposure Gly II activity of salt sensitive BRRI dhan 49 was increased only under mild salt stress. On the other hand tolerant BRRI dhan54 increased its activity in both stress levels (Figure 9(b)). Enhanced Gly II activity in response to salt stress was also observed in our previous study [90]. When these cultivars were supplied with exogenous Pro or GB with salt stress their Gly II activities significantly enhanced. Pro- and GB-induced upregulation of glyoxalase enzymes and subsequent salt stress tolerance were also reported by other researchers [29, 32]. Engineering of glyoxalase pathway enzymes in different plant species reduced MG content under salt that was correlated to GSHbased MG detoxification system which reduced oxidative damage $[16,17,91-93]$. These results are in line with our findings. If the glyoxalase enzymes of two cultivars are compared it can be said that the tolerant BRRI dhan54 had higher Gly I and Gly II activities in all the cases, compared to BRRI dhan49. Even if the GSH level of these two cultivars are compared it is clear that BRRI dhan 54 is better performer as it maintained higher GSH levels both under salt stress conditions with or without Pro and GB (Figure 5(b)). The higher GSH level with higher Gly I and Gly II activities are evidence for efficient glyoxalase system for conferring salt stress tolerance $[18,90]$. Thus higher Gly I and Gly II activities with higher GSH level induced by Pro and GB have made BRRI dhan54 more salt tolerant cultivar than BRRI dhan 49.

\section{Conclusion}

Considering the above results we, therefore, conclude that exogenous Pro and GB are effective protectants to improve short-term salt tolerance both in salt sensitive BRRI dhan 49 and salt tolerant BRRI dhan54 as Pro and GB effectively maintained better physiological conditions and significantly alleviated oxidative damages of rice seedlings by enhancing the antioxidant and glyoxalase systems. In all the cases BRRI dhan54 was a better performer under salt stress. Although the studied antioxidant and glyoxalase enzymes were improved by both the osmoprotectants; the GB could not restore the nonenzymatic antioxidants of salt sensitive cultivar BRRI dhan 49 in some cases. Considering these facts it can be assumed that Pro is good for salt sensitive cultivar at present studied condition. From the comparative studies of salt tolerant and sensitive cultivars, it can be said that enhancement of tolerance by Pro and GB even in the salt sensitive cultivar is an interesting point and this result deserves further intrinsic researches. The dose duration dependent study with Pro and GB in different salinity levels might be elucidated. Mechanisms of Pro and GB as osmoprotectants, free radical scavengers, enzyme activators, or as regulators of other physiological processes were stated in many articles but merely studied under different stress conditions. Studies on their protective mechanisms and signaling cascades are the further scope of research.

\section{Conflict of Interests}

The authors declare that there is no conflict of interests regarding the publication of this paper.

\section{Acknowledgments}

This work was partially supported by Sher-e-Bangla Agricultural University Research System (SAURES) Grant no. SAU/SAURES/13/38 to Mirza Hasanuzzaman. The authors thank Dr. M.D. Motiar Rohman, Molecular Plant Breeding Laboratory, Bangladesh Agricultural Research Institute, Gazipur, for his kind help in measuring enzymatic activities. The authors would like to thank Mrs. Ratna Rani Majumder, Genetic resource and Seed Division, Bangladesh Rice Research Institute, Gazipur, for generously providing quality seeds of rice.

\section{References}

[1] M. Hasanuzzaman, M. Fujita, M. N. Islam, K. U. Ahamed, and K. Nahar, "Performance of four irrigated rice varieties 
under different levels of salinity stress," International Journal of Integrative Biology, vol. 6, pp. 85-90, 2009.

[2] M. Hasanuzzaman, M. A. Hossain, and M. Fujita, "Nitric oxide modulates antioxidant defense and the methylglyoxal detoxification system and reduces salinity-induced damage of wheat seedlings," Plant Biotechnology Reports, vol. 5, no. 4, pp. 353-365, 2011.

[3] M. Hasanuzzaman, M. A. Hossain, and M. Fujita, "Seleniuminduced up-regulation of the antioxidant defense and methylglyoxal detoxification system reduces salinity-induced damage in rapeseed seedlings," Biological Trace Element Research, vol. 143, no. 3, pp. 1704-1721, 2011.

[4] M. Hasanuzzaman, M. A. Hossain, J. A. Teixeira da Silva, and M. Fujita, "Plant responses and tolerance to abiotic oxidative stress: antioxidant defense is a key factor," in Crop Stress and Its Management: Perspectives and Strategies, V. Bandi, A. K. Shanker, C. Shanker, and M. Mandapaka, Eds., pp. 261-316, Springer, Berlin, Germany, 2012.

[5] M. Hasanuzzaman, M. A. Hossain, and M. Fujita, "Exogenous selenium pretreatment protects rapeseed seedlings from cadmium-induced oxidative stress by upregulating antioxidant defense and methylglyoxal detoxification systems," Biological Trace Element Research, vol. 149, no. 2, pp. 248-261, 2012.

[6] M. Hasanuzzaman, K. Nahar, M. Alam, and M. Fujita, "Exogenous nitric oxide alleviates high temperature induced oxidative stress in wheat (Triticum aestivum) seedlings by modulating the antioxidant defense and glyoxalase system," Australian Journal of Crop Science, vol. 6, no. 8, pp. 1314-1323, 2012.

[7] M. Hasanuzzaman, K. Nahar, and M. Fujita, "Plant response to salt stress and role of exogenous protectants to mitigate saltinduced damages," in Ecophysiology and Responses of Plants under Salt Stress, P. Ahmad, M. M. Azooz, and M. N. V. Prasad, Eds., pp. 25-87, Springer, New York, NY, USA, 2013.

[8] M. Hasanuzzaman, K. Nahar, and M. Fujita, "Extreme temperatures, oxidative stress and antioxidant defense in plants," in Abiotic Stress-Plant Responses and Applications in Agriculture, K. Vahdati and C. Leslie, Eds., pp. 169-205, InTech, Rijeka,Croatia, 2013.

[9] M. Hasanuzzaman, K. Nahar, S. S. Gill, and M. Fujita, "Drought stress responses in plants, oxidative stress and antioxidant defense," in Climate Change and Plant Abiotic Stress Tolerance, S. S. Gill and N. Tuteja, Eds., pp. 209-249, Wiley, Weinheim, Germany, 2014.

[10] M. Hasanuzzaman and M. Fujita, "Exogenous sodium nitroprusside alleviates arsenic-induced oxidative stress in wheat (Triticum aestivum L.) seedlings by enhancing antioxidant defense and glyoxalase system," Ecotoxicology, vol. 22, no. 3, pp. 584-596, 2013.

[11] W. Wang, B. Vinocur, O. Shoseyour, and A. Altman, "Biotechnology of plant osmotic stress tolerance: physiological and molecular considerations," Acta Horticulturae, vol. 590, pp. 286-292, 2001.

[12] H. R. Athar and M. Ashraf, "Strategies for crop improvement against salt and water stress: an overview," in Salinity and Water Stress: Improving Crop Efficiency, M. Ashraf, M. Ozturk, and H. R. Athar, Eds., pp. 1-16, Springer, Dordrecht, The Netherlands, 2009.

[13] E. A. Bray, J. Bailey-Serres, and E. Weretilnyk, "Responses to abiotic stress," in Biochemistry and Molecular Biology of Plants, B. B. Buchanan, W. Gruissem, and R. Jones, Eds., pp. 1158-1203, American Society of Plant Physiologists, Rockville, Maryland, 2000 .
[14] S. K. Yadav, S. L. Singla-Pareek, and S. K. Sopory, "An overview on the role of methylglyoxal and glyoxalases in plants," Drug Metabolism and Drug Interactions, vol. 23, no. 1-2, pp. 51-68, 2008.

[15] V. Kumar and S. K. Yadav, "Proline and betaine provide protection to antioxidant and methylglyoxal detoxification systems during cold stress in Camellia sinensis (L.) O. Kuntze," Acta Physiologiae Plantarum, vol. 31, no. 2, pp. 261-269, 2009.

[16] S. K. Yadav, S. L. Singla-Pareek, M. Ray, M. K. Reddy, and S. K. Sopory, "Methylglyoxal levels in plants under salinity stress are dependent on glyoxalase I and glutathione," Biochemical and Biophysical Research Communications, vol. 337, no. 1, pp. 61-67, 2005.

[17] S. K. Yadav, S. L. Singla-Pareek, M. K. Reddy, and S. K. Sopory, "Transgenic tobacco plants overexpressing glyoxalase enzymes resist an increase in methylglyoxal and maintain higher reduced glutathione levels under salinity stress," FEBS Letters, vol. 579, no. 27, pp. 6265-6271, 2005.

[18] M. Hasanuzzaman and M. Fujita, "Selenium pretreatment upregulates the antioxidant defense and methylglyoxal detoxification system and confers enhanced tolerance to drought stress in rapeseed seedlings," Biological Trace Element Research, vol. 143, no. 3, pp. 1758-1776, 2011.

[19] M. L. Lopez and S. M. E. Satti, "Calcium and potassium enhanced growth and yield of tomato under sodium chloride stress," Plant Sciience, vol. 114, no. 1, pp. 19-27, 1996.

[20] S. Noreen, H. U. R. Athar, and M. Ashraf, "Interactive effects of watering regimes and exogenously applied osmoprotectants on earliness indices and leaf area index in cotton (Gossypium hirsutum L.) crop," Pakistan Journal of Botany, vol. 45, pp. 18731881, 2013.

[21] L. Szabados and A. Savouré, "Proline: a multifunctional amino acid," Trends in Plant Science, vol. 15, no. 2, pp. 89-97, 2010.

[22] M. Ashraf and M. R. Foolad, "Roles of glycine betaine and proline in improving plant abiotic stress resistance," Environmental and Experimental Botany, vol. 59, no. 2, pp. 206-216, 2007.

[23] T. H. H. Chen and N. Murata, "Glycinebetaine: an effective protectant against abiotic stress in plants," Trends in Plant Science, vol. 13, no. 9, pp. 499-505, 2008.

[24] S. Hayat, Q. Hayat, M. N. Alyemeni, A. S. Wani, J. Pichtel, and A. Ahmad, "Role of proline under changing environments: a review," Plant Signaling and Behavior, vol. 7, no. 11, pp. 1-11, 2012.

[25] V. Y. Patade, V. H. Lokhande, and P. Suprasanna, "Exogenous application of proline alleviates salt induced oxidative stress more efficiently than glycine betaine in sugarcane cultured cells," Sugar Tech, vol. 16, no. 1, pp. 22-29, 2014.

[26] M. Ashraf and P. J. C. Harris, "Potential biochemical indicators of salinity tolerance in plants," Plant Science, vol. 166, no. 1, pp. 3-16, 2004.

[27] S. H. Raza, H. U. R. Athar, and M. Ashraf, "Influence of exogenously applied glycinebetaine on the photosynthetic capacity of two differently adapted wheat cultivars under salt stress," Pakistan Journal of Botany, vol. 38, no. 2, pp. 241-251, 2006.

[28] M. A. Hoque, M. N. A. Banu, E. Okuma et al., "Exogenous proline and glycinebetaine increase $\mathrm{NaCl}$-induced ascorbateglutathione cycle enzyme activities, and proline improves salt tolerance more than glycinebetaine in tobacco Bright Yellow-2 suspension-cultured cells," Journal of Plant Physiology, vol. 164, no. 11, pp. 1457-1468, 2007.

[29] M. A. Hoque, M. N. A. Banu, Y. Nakamura, Y. Shimoishi, and Y. Murata, "Proline and glycinebetaine enhance antioxidant defense and methylglyoxal detoxification systems and reduce 
NaCl-induced damage in cultured tobacco cells," Journal of Plant Physiology, vol. 165, no. 8, pp. 813-824, 2008.

[30] M. T. Sakr, N. M. El-Sarkassy, and M. P. Fuller, "Osmoregulators proline and glycine betaine counteract salinity stress in canola," Agronomy for Sustainable Development, vol. 32, no. 3, pp. 747754,2012

[31] K. Nawaz and M. Ashraf, "Exogenous application of glycinebetaine modulates activities of antioxidants in maize plants subjected to salt stress," Journal of Agronomy and Crop Science, vol. 196, no. 1, pp. 28-37, 2010.

[32] M. N. A. Banu, M. A. Hoque, M. Watanabe-Sugimoto et al., "Proline and glycinebetaine ameliorated $\mathrm{NaCl}$ stress via scavenging of hydrogen peroxide and methylglyoxal but not superoxide or nitric oxide in tobacco cultured cells," Bioscience, Biotechnology and Biochemistry, vol. 74, no. 10, pp. 2043-2049, 2010.

[33] H. D. Barrs and P. E. Weatherley, "A re-examination of the relative turgidity technique for estimating water deficits in leaves," Australian Journal of Biological Science, vol. 15, pp. 413428, 1962.

[34] D. T. Arnon, "Copper enzymes in isolated chloroplasts polyphenaloxidase in Beta vulgaris," Plant Physiology, vol. 24, pp. 1-15, 1949.

[35] L. S. Bates, R. P. Waldren, and I. D. Teare, "Rapid determination of free proline for water-stress studies," Plant and Soil, vol. 39, no. 1, pp. 205-207, 1973.

[36] R. L. Heath and L. Packer, "Photoperoxidation in isolated chloroplasts. I. Kinetics and stoichiometry of fatty acid peroxidation," Archives of Biochemistry and Biophysics, vol. 125, no. 1, pp. 189-198, 1968.

[37] C. W. Yu, T. M. Murphy, and C. H. Lin, "Hydrogen peroxideinduced chilling tolerance in mung beans mediated through ABA-independent glutathione accumulation," Functional Plant Biology, vol. 30, no. 9, pp. 955-963, 2003.

[38] C. Huang, W. He, J. Guo, X. Chang, P. Su, and L. Zhang, "Increased sensitivity to salt stress in an ascorbate-deficient Arabidopsis mutant," Journal of Experimental Botany, vol. 56, no. 422, pp. 3041-3049, 2005.

[39] A. Paradiso, R. Berardino, M. C. de Pinto et al., "Increase in ascorbate-glutathione metabolism as local and precocious systemic responses induced by cadmium in durum wheat plants," Plant and Cell Physiology, vol. 49, no. 3, pp. 362-374, 2008.

[40] M. M. Bradford, "A rapid and sensitive method for the quantitation of microgram quantities of protein utilizing the principle of protein dye binding," Analytical Biochemistry, vol. 72, no. 1-2, pp. 248-254, 1976.

[41] A. Doderer, I. Kokkelink, S. van der Veen, B. E. Valk, A. W. Schram, and A. C. Douma, "Purification and characterization of two lipoxygenase isoenzymes from germinating barley," Biochimica et Biophysica Acta, vol. 1120, no. 1, pp. 97-104, 1992.

[42] W. F. Beyer Jr. and I. Fridovich, "Assaying for superoxide dismutase activity: some large consequences of minor changes in conditions," Analytical Biochemistry, vol. 161, no. 2, pp. 559$566,1987$.

[43] Y. Nakano and K. Asada, "Hydrogen peroxide is scavenged by ascorbate-specific peroxidase in spinach chloroplasts," Plant and Cell Physiology, vol. 22, no. 5, pp. 867-880, 1981.

[44] M. A. Hossain, Y. Nakano, and K. Asada, "Monodehydroascorbate reductase in spinach chloroplasts and its participation in regeneration of ascorbate for scavenging hydrogen peroxide," Plant and Cell Physiology, vol. 25, no. 3, pp. 385-395, 1984.
[45] M. Z. Hossain, M. D. Hossain, and M. Fujita, "Induction of pumpkin glutathione S-transferases by different stresses and its possible mechanisms," Biologia Plantarum, vol. 50, no. 2, pp. 210-218, 2006.

[46] A. C. Elia, R. Galarini, M. I. Taticchi, A. J. M. Dörr, and L. Mantilacci, "Antioxidant responses and bioaccumulation in Ictalurus melas under mercury exposure," Ecotoxicology and Environmental Safety, vol. 55, no. 2, pp. 162-167, 2003.

[47] G. B. Principato, G. Rosi, and V. Talesa, "Purification and characterization of two forms of glyoxalase II from the liver and brain of Wistar rats," Biochimica et Biophysica Acta, vol. 911, no. 3, pp. 349-355, 1987.

[48] Addinsoft, XLSTAT 2013 v.2013.6.03: Data analysis and statistics software for Microsoft Excel, Addinsoft, Paris, France, 2013.

[49] N. Nounjan, P. T. Nghia, and P. Theerakulpisut, "Exogenous proline and trehalose promote recovery of rice seedlings from salt-stress and differentially modulate antioxidant enzymes and expression of related genes," Journal of Plant Physiology, vol. 169, no. 6, pp. 596-604, 2012.

[50] L. Vysotskaya, P. E. Hedley, G. Sharipova et al., "Effect of salinity on water relations of wild barley plants differing in salt tolerance," AoB Plant, vol. 2010, p. plq006, 2010.

[51] N. Chaparzadeh and F. Mehrnejad, "Oxidative markers in five Iranian alfalfa (Medicago sativa L.) cultivars under salinity stress," Iranian Journal of Plant Physiology, vol. 3, pp. 793-799, 2013.

[52] N. Katerji, J. W. van Hoorn, A. Hamdy, M. Mastrorilli, and E. Moukarzel, "Osmotic adjustment of sugar beets in response to soil salinity and its influence on stomatal conductance, growth and yield," Agricultural Water Management, vol. 34, no. 1, pp. 57-69, 1997.

[53] K. Nawaz and M. Ashraf, "Improvement in salt tolerance of maize by exogenous application of glycinebetaine: growth and water relations," Pakistan Journal of Botany, vol. 39, no. 5, pp. 1647-1653, 2007.

[54] H. M. A. El-Samad, M. A. K. Shaddad, and N. Barakat, "Improvement of plants salt tolerance by exogenous application of amino acids," Journal of Medicinal Plant Research, vol. 5, no. 24, pp. 5692-5699, 2011.

[55] K. Maxwell and G. N. Johnson, "Chlorophyll fluorescence-a practical guide," Journal of Experimental Botany, vol. 51, no. 345, pp. 659-668, 2000.

[56] M. R. Amirjani, "Effect of salinity stress on growth, sugar content, pigments and enzyme activity of rice," International Journal of Botany, vol. 7, no. 1, pp. 73-81, 2011.

[57] N. Garg and G. Manchanda, "ROS generation in plants: boon or bane?” Plant Biosystems, vol. 143, no. 1, pp. 81-96, 2009.

[58] M. M. Azooz, A. M. Ismail, and M. F. A. Elhamd, "Growth, lipid peroxidation and antioxidant enzyme activities as a selection criterion for the salt tolerance of maize cultivars grown under salinity stress," International Journal of Agriculture and Biology, vol. 11, no. 1, pp. 21-26, 2009.

[59] P. Saha, P. Chatterjee, and A. K. Biswas, "NaCl pretreatment alleviates salt stress by enhancement of antioxidant defense system and osmolyte accumulation in mungbean (Vigna radiata L. Wilczek)," Indian Journal of Experimental Biology, vol. 48, no. 6, pp. 593-600, 2010.

[60] W. Weisany, Y. Sohrabi, G. Heidari, A. Siosemardeh, and K. Ghassemi-Golezani, "Changes in antioxidant enzymes activity and plant performance by salinity stress and zinc application in soybean (Glycine max L.)," Plant Omics Journal, vol. 5, no. 2, pp. 60-67, 2012. 
[61] Z. Yan, S. Guo, S. Shu, J. Sun, and T. Tezuka, "Effects of proline on photosynthesis, root reactive oxygen species (ROS) metabolism in two melon cultivars (Cucumis melo L.) under $\mathrm{NaCl}$ stress," African Journal of Biotechnology, vol. 10, no. 80, pp. 18381-18390, 2011.

[62] N. Nounjan and P. Theerakulpisut, "Effects of exogenous proline and trehalose on physiological responses in rice seedlings during salt-stress and after recovery," Plant, Soil and Environment, vol. 58, no. 7, pp. 309-315, 2012.

[63] A. Aziz and F. Larher, "Osmotic stress induced changes in lipid composition and peroxidation in leaf discs of Brassica napus L," Journal of Plant Physiology, vol. 153, no. 5-6, pp. 754-762, 1998.

[64] A. Molassiotis, T. Sotiropoulos, G. Tanou, G. Diamantidis, and I. Therios, "Boron-induced oxidative damage and antioxidant and nucleolytic responses in shoot tips culture of the apple rootstock EM 9 (Malus domestica Borkh)," Environmental and Experimental Botany, vol. 56, no. 1, pp. 54-62, 2006.

[65] E. Sánchez-Rodríguez, M. D. M. Rubio-Wilhelmi, B. Blasco, R. Leyva, L. Romero, and J. M. Ruiz, "Antioxidant response resides in the shoot in reciprocal grafts of drought-tolerant and drought-sensitive cultivars in tomato under water stress," Plant Science, vol. 188-189, pp. 89-96, 2012.

[66] G. M. Pastori, G. Kiddle, J. Antoniw et al., "Leaf vitamin C contents modulate plant defense transcripts and regulate genes that control development through hormone signaling," The Plant Cell, vol. 15, no. 4, pp. 939-951, 2003.

[67] L. Ball, G.-P. Accotto, U. Bechtold et al., "Evidence for a direct link between glutathione biosynthesis and stress defense gene expression in Arabidopsis," The Plant Cell, vol. 16, no. 9, pp. 2448-2462, 2004.

[68] A. Shalata and P. M. Neumann, "Exogenous ascorbic acid (vitamin C) increases resistance to salt stress and reduces lipid peroxidation," Journal of Experimental Botany, vol. 52, no. 364, pp. 2207-2211, 2001.

[69] J. M. Li and H. Jin, "Regulation of brassinosteroid signaling," Trends in Plant Science, vol. 12, no. 1, pp. 37-41, 2007.

[70] N. Kumar, M. Pal, A. Singh, R. K. SaiRam, and G. C. Srivastava, "Exogenous proline alleviates oxidative stress and increase vase life in rose (Rosa hybrida L. 'Grand Gala')," Scientia Horticulturae, vol. 127, no. 1, pp. 79-85, 2010.

[71] P. Ghezzi, V. Bonetto, and M. Fratelli, "Thiol-disulfide balance: from the concept of oxidative stress to that of redox regulation," Antioxidants and Redox Signaling, vol. 7, no. 7-8, pp. 964-972, 2005.

[72] N. Ghosh, M. K. Adak, P. D. Ghosh, S. Gupta, D. N. S. Gupta, and C. Mandal, "Differential responses of two rice varieties to salt stress," Plant Biotechnology Reports, vol. 5, no. 1, pp. 89-103, 2011.

[73] A. Mhamdi, G. Queval, S. Chaouch, S. Vanderauwera, F. van Breusegem, and G. Noctor, "Catalase function in plants: a focus on Arabidopsis mutants as stress-mimic models," Journal of Experimental Botany, vol. 61, no. 15, pp. 4197-4220, 2010.

[74] M. Gupta, P. Sharma, N. B. Sarin, and A. K. Sinha, "Differential response of arsenic stress in two varieties of Brassica juncea L," Chemosphere, vol. 74, no. 9, pp. 1201-1208, 2009.

[75] I. Khan, A. Ahmad, and M. Iqbal, "Modulation of antioxidant defence system for arsenic detoxification in Indian mustard," Ecotoxicology and Environmental Safety, vol. 72, no. 2, pp. 626634, 2009.

[76] A. H. Sekmen, I. Türkan, and S. Takio, "Differential responses of antioxidative enzymes and lipid peroxidation to salt stress in salt-tolerant Plantago maritima and salt-sensitive Plantago media," Physiologia Plantarum, vol. 131, no. 3, pp. 399-411, 2007.
[77] C.-J. Lin, C.-Y. Li, S.-K. Lin et al., "Influence of high temperature during grain filling on the accumulation of storage proteins and grain quality in rice (Oryza sativa L.)," Journal of Agricultural and Food Chemistry, vol. 58, no. 19, pp. 10545-10552, 2010.

[78] C. Ben Ahmed, B. Ben Rouina, S. Sensoy, M. Boukhriss, and F. Ben Abdullah, "Exogenous proline effects on photosynthetic performance and antioxidant defense system of young olive tree," Journal of Agricultural and Food Chemistry, vol. 58, no. 7, pp. 4216-4222, 2010.

[79] A. E. Eltayeb, N. Kawano, G. H. Badawi et al., "Enhanced tolerance to ozone and drought stresses in transgenic tobacco overexpressing dehydroascorbate reductase in cytosol," Physiologia Plantarum, vol. 127, no. 1, pp. 57-65, 2006.

[80] A. E. Eltayeb, N. Kawano, G. H. Badawi et al., "Overexpression of monodehydroascorbate reductase in transgenic tobacco confers enhanced tolerance to ozone, salt and polyethylene glycol stresses," Planta, vol. 225, no. 5, pp. 1255-1264, 2007.

[81] Z. Wang, Y. Xiao, W. Chen, K. Tang, and L. Zhang, "Increased vitamin $\mathrm{C}$ content accompanied by an enhanced recycling pathway confers oxidative stress tolerance in Arabidopsis," Journal of Integrative Plant Biology, vol. 52, no. 4, pp. 400-409, 2010.

[82] A. S. V. Chalapathi Rao and A. R. Reddy, "Glutathione reductase: a putative redox regulatory system in the plant cells," in Sulfur Assimilation and Abiotic Stresses in Plants, N. A. Khan, S. Singh, and S. Umar, Eds., pp. 111-147, Springer, Berlin, Germany, 2008.

[83] C. H. Pang and B. S. Wang, "Role of ascorbate peroxidase and glutathione reductase in ascorbate-glutathione cycle and stress tolerance in plants," in Ascorbate-Glutathione Pathway and Stress Tolerance in Plants, N. A. Anjum, M. T. Chan, and S. Umar, Eds., pp. 91-112, Springer, Dordrecht, The Netherlands, 2010.

[84] K. Aghaei, A. A. Ehsanpour, and S. Komatsu, "Potato responds to salt stress by increased activity of antioxidant enzymes," Journal of Integrative Plant Biology, vol. 51, no. 12, pp. 1095-1103, 2009.

[85] R. Brigelius-Flohé and L. Flohé, "Is there a role of glutathione peroxidases in signaling and differentiation?" BioFactors, vol. 17, no. 1-4, pp. 93-102, 2003.

[86] S. Sai Kachout, K. J. Hamza, N. Karray Bouraoui, L. C. Leclerc, and Z. Ouerghi, "Salt-induced changes in antioxidative enzyme activities in shoot tissues of two Atriplex varieties," Notulae Botanicae Horti Agrobotanici, vol. 41, pp. 115-121, 2013.

[87] D. P. Dixon, M. Skipsey, and R. Edwards, "Roles for glutathione transferases in plant secondary metabolism," Phytochemistry, vol. 71, no. 4, pp. 338-350, 2010.

[88] P. J. Thornalley, “The glyoxalase system: new developments towards functional characterization of a metabolic pathway fundamental to biological life," Biochemical Journal, vol. 269, no. 1, pp. 1-11, 1990.

[89] H. El-Shabrawi, B. Kumar, T. Kaul, M. K. Reddy, S. L. SinglaPareek, and S. K. Sopory, "Redox homeostasis, antioxidant defense, and methylglyoxal detoxification as markers for salt tolerance in Pokkali rice," Protoplasma, vol. 245, no. 1, pp. 85-96, 2010.

[90] K. Nahar, M. Hasanuzzaman, M. M. Alam, and M. Fujita, "Exogenous glutathione alleviates short-term abiotic stress by modulating antioxidant defense and methylglyoxal detoxification system in V. radiata seedlings," in Proceedings of the Annual Main Meeting of the Society for Experimental Biology (SEB '12), Salzburg, Austria, July 2012. 
[91] V. S. Reddy and S. K. Sopory, "Glyoxalase I from Brassica juncea: molecular cloning, regulation and its over-expression confer tolerance in transgenic tobacco under stress," The Plant Journal, vol. 17, no. 4, pp. 385-395, 1999.

[92] S. L. Singla-Pareek, S. K. Yadav, A. Pareek, M. K. Reddy, and S. K. Sopory, "Transgenic tobacco overexpressing glyoxalase pathway enzymes grow and set viable seeds in zinc-spiked soils," Plant Physiology, vol. 140, no. 2, pp. 613-623, 2006.

[93] S. L. Singla-Pareek, S. K. Yadav, A. Pareek, M. K. Reddy, and S. K. Sopory, "Enhancing salt tolerance in a crop plant by overexpression of glyoxalase II," Transgenic Research, vol. 17, no. 2, pp. 171-180, 2008. 

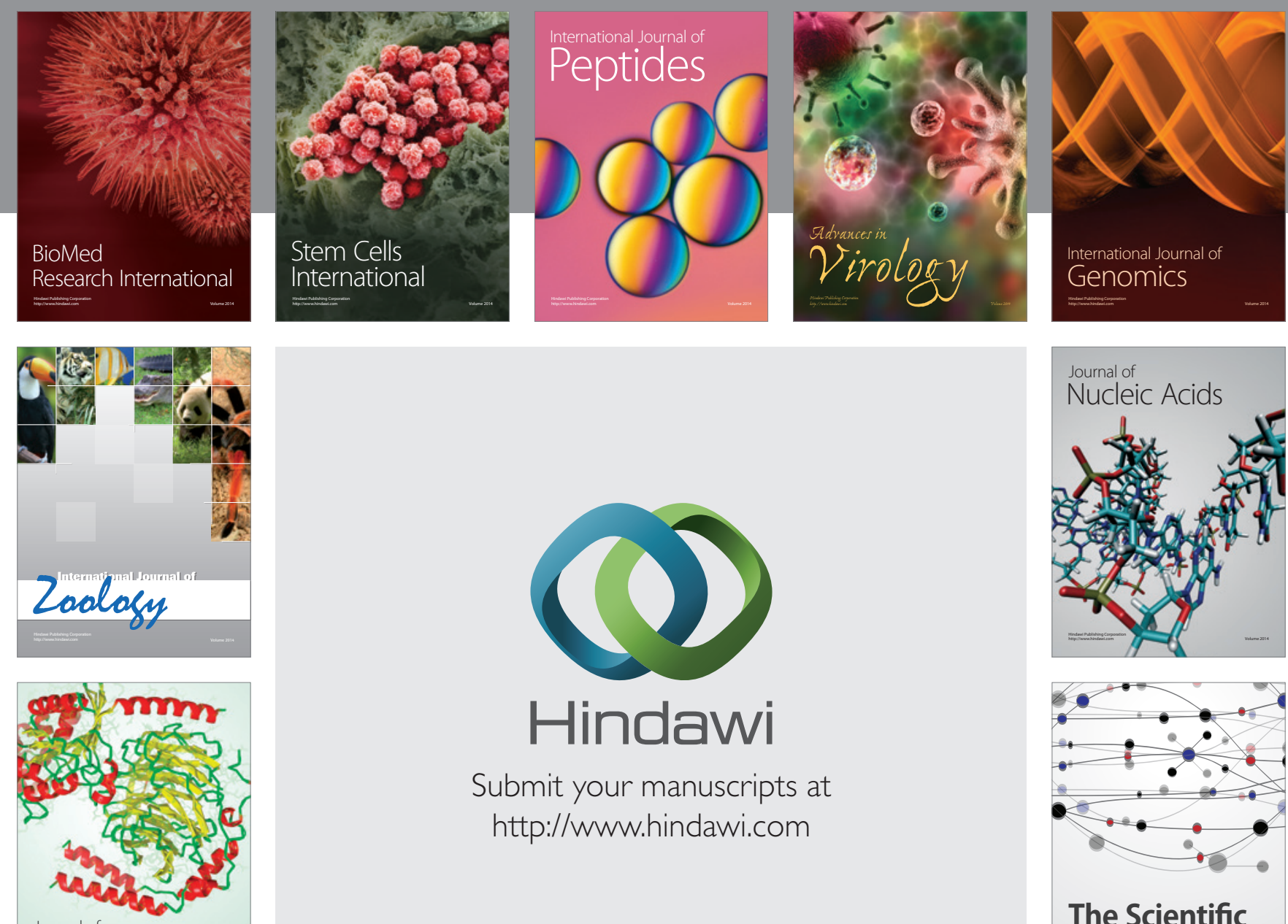

Submit your manuscripts at

http://www.hindawi.com

Journal of
Signal Transduction
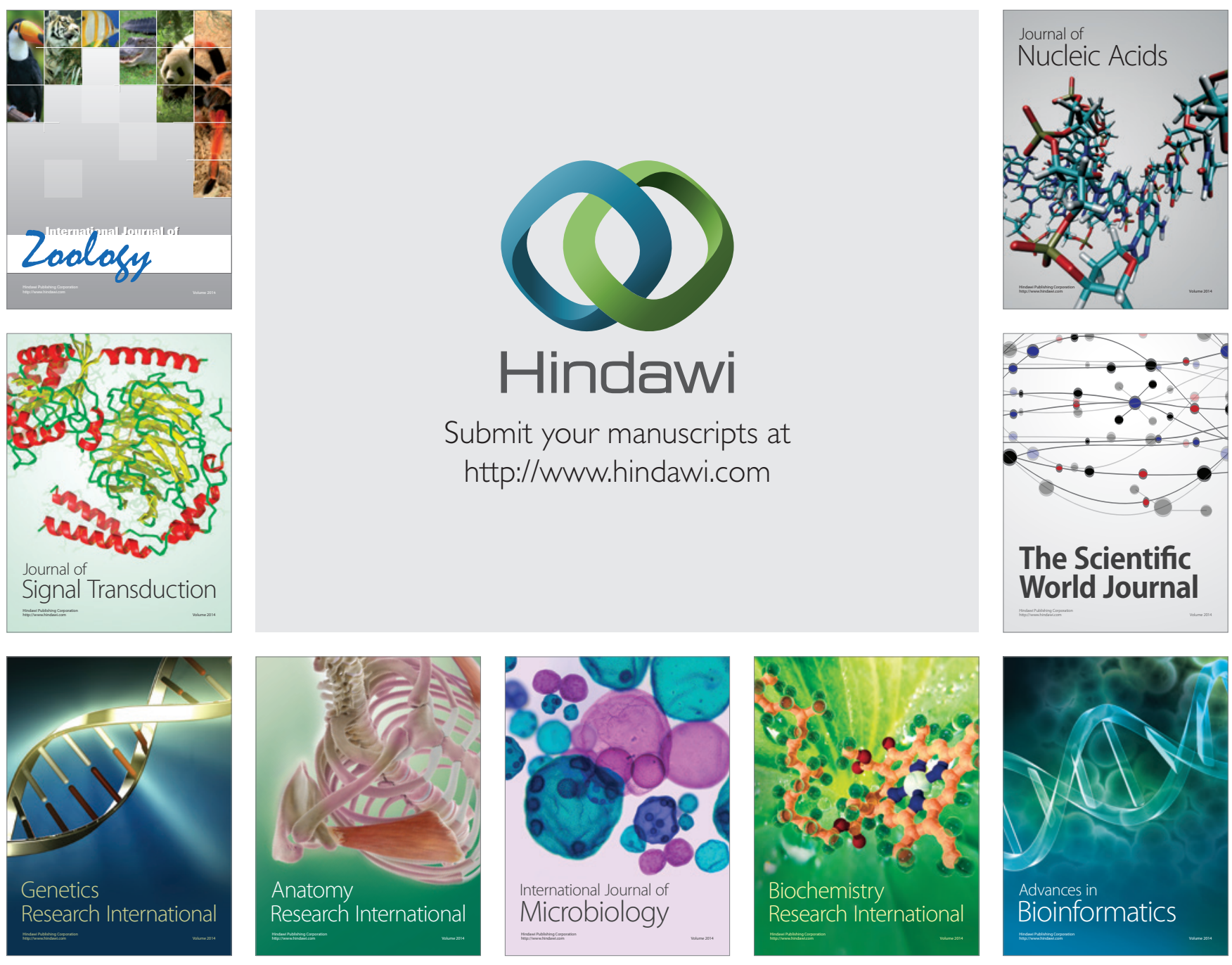

The Scientific World Journal
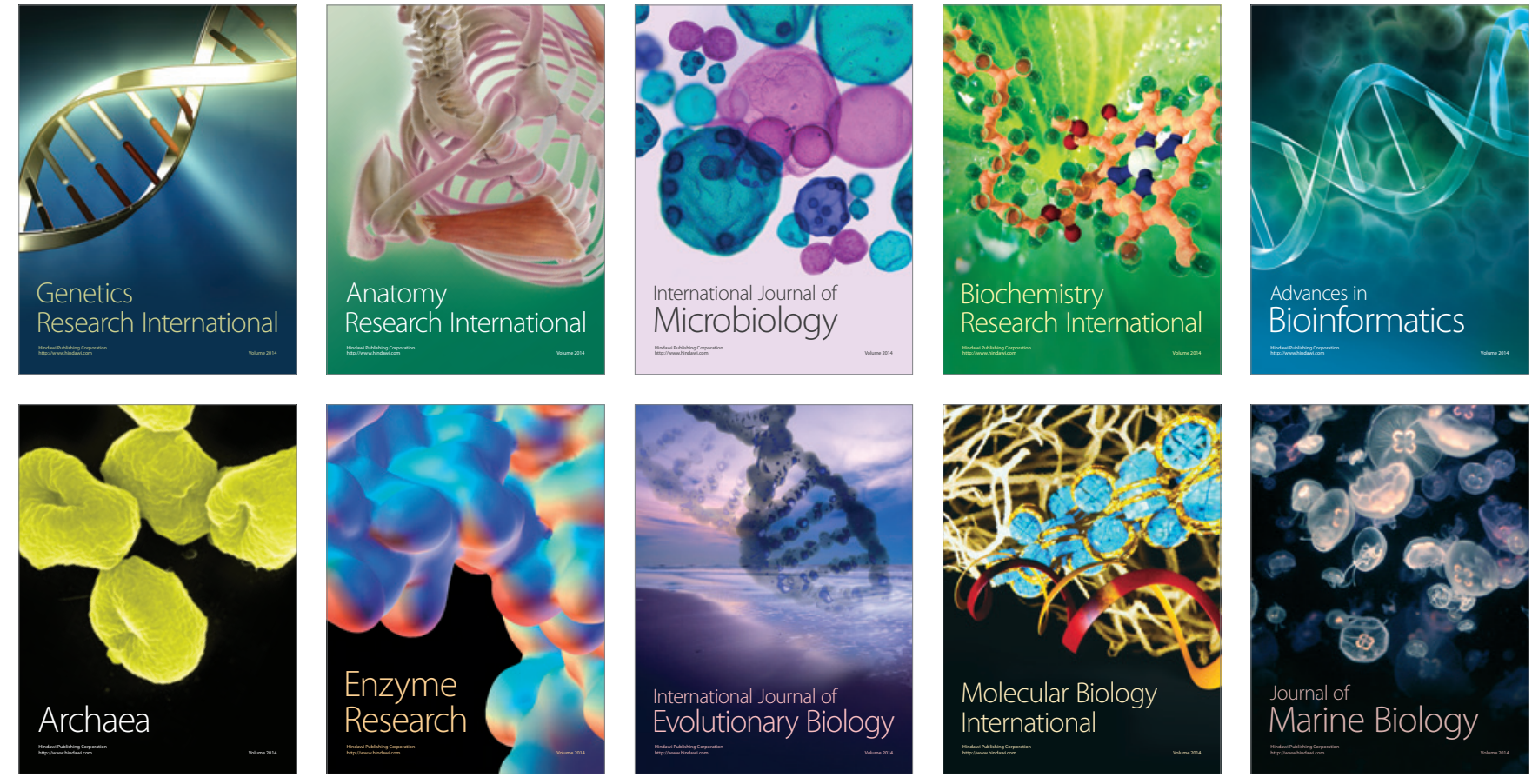